\title{
Maternal High-Fat Diet and Fetal Programming: Increased Proliferation of Hypothalamic Peptide-Producing Neurons That Increase Risk for Overeating and Obesity
}

\author{
Guo-Qing Chang, Valeriya Gaysinskaya, Olga Karatayev, and Sarah F. Leibowitz \\ The Rockefeller University, New York, New York 10065
}

\begin{abstract}
Recent studies in adult and weanling rats show that dietary fat, in close association with circulating lipids, can stimulate expression of hypothalamic peptides involved in controlling food intake and body weight. In the present study, we examined the possibility that a fat-rich diet during pregnancy alters the development of these peptide systems in utero, producing neuronal changes in the offspring that persist postnatally in the absence of the diet and have long-term consequences. The offspring of dams on a high-fat diet (HFD) versus balanced diet (BD), from embryonic day 6 to postnatal day 15 (P15), showed increased expression of orexigenic peptides, galanin, enkephalin, and dynorphin, in the paraventricular nucleus and orexin and melanin-concentrating hormone in the perifornical lateral hypothalamus. The increased density of these peptide-expressing neurons, evident in newborn offspring as well as P15 offspring crossfostered at birth to dams on the BD, led us to examine events that might be occurring in utero. During gestation, the HFD stimulated the proliferation of neuroepithelial and neuronal precursor cells of the embryonic hypothalamic third ventricle. It also stimulated the proliferation and differentiation of neurons and their migration toward hypothalamic areas where ultimately a greater proportion of the new neurons expressed the orexigenic peptides. This increase in neurogenesis, closely associated with a marked increase in lipids in the blood, may have a role in producing the long-term behavioral and physiological changes observed in offspring after weaning, including an increase in food intake, preference for fat, hyperlipidemia, and higher body weight.
\end{abstract}

Key words: maternal high-fat diet; lipids; hypothalamus; orexigenic peptides; neurogenesis; food intake

\section{Introduction}

Childhood obesity and type II diabetes have increased markedly in industrialized countries, more than doubling over the past 30 years (Rocchini, 2002). Clinical and animal studies have attributed this rise, in part, to fetal programming produced by maternal obesity and diabetes, which raise the offspring's long-term risk for these disorders, and by manipulations of maternal nutrition, which can affect the offspring's dietary preferences (McMillen and Robinson, 2005; Plagemann, 2006; Taylor and Poston, 2007). Hypothalamic systems controlling food intake and body weight are affected by these perinatal manipulations and may be involved in mediating the long-term behavioral and physiological disturbances (McMillen and Robinson, 2005; Taylor and Poston, 2007). Studies to date have generally involved maternal manipulations such as postnatal undernutrition or overnutrition, gestational diabetes, or low-protein diets, and have revealed changes in feeding-related peptides, particularly neu-

\footnotetext{
Received June 10, 2008; revised 0ct. 3, 2008; accepted 0ct. 14, 2008.

This work was supported by National Institutes of Health Grant MH 43422/DA 21518. We thank Dr. Rashed Ahsan for his help with some of the radioimmunoassays, Dr. Irene Yaroslavsky for her help with the figures, Drs. Nicole Avena, Akira Akabayashi, and Lucy Brown for their critical reading of this manuscript, and Joe Shuluk, Agnes Kim Greg Pace, Helen Martirosova, and Jesline Alexander for technical assistance.

This article is freely available online through the J Neurosci Open Choice option.

Correspondence should be addressed to Sarah F. Leibowitz, The Rockefeller University, 1230 York Avenue, New York, NY 10065. E-mail: leibow@rockefeller.edu.

DOI:10.1523/JNEUROSCI.2642-08.2008

Copyright $\odot 2008$ Society for Neuroscience $\quad$ 0270-6474/08/2812107-13\$15.00/0
}

ropeptide Y (NPY) and galanin (GAL), in the arcuate nucleus (ARC) of weanling rats (Plagemann et al., 1999, 2000; López et al., 2005; Plagemann, 2006). It is not clear whether these effects are a consequence of changes in the offspring's body weight and adiposity-related hormones, insulin and leptin, or whether they reflect developmental changes in utero that persist over the long term. The brain is clearly affected by nutrition during pregnancy, as indicated by studies measuring whole-brain NPY in embryos of diabetic dams or dams on a low-protein diet (Singh et al., 1997; Terroni et al., 2005) and also brain growth or cell generation in offspring of malnourished dams (Debassio et al., 1994; Gressens et al., 1997; Plagemann et al., 2000).

To further elucidate mechanisms in utero that may underlie fetal programming related to maternal nutrition, we focused the present study on a specific macronutrient, dietary fat, which can be manipulated for brief periods without altering the body weight and hormone levels of dams and their offspring (Khan et al., 2005). In adult rats, the consumption of a high-fat diet or injection of a fat emulsion stimulates the expression of orexigenic peptides in the paraventricular nucleus (PVN) and perifornical lateral hypothalamus (PFLH), but not the ARC. These include GAL, enkephalin (ENK), and dynorphin (DYN) in the PVN and orexin (ORX) in the PFLH, whose expression is strongly, positively related to circulating levels of lipids, in particular triglycerides (TG) (Leibowitz and Wortley, 2004; Leibowitz et al., 2004; Chang et al., 2007), and whose injection preferentially stimulates 
intake of a high-fat diet (Zhang et al., 1998; Leibowitz, 2000; Clegg et al., 2002; Yun et al., 2005). Whereas a high-fat diet during pregnancy and lactation is known to have long-term physiological effects in adult offspring (Taylor et al., 2005; Férézou-Viala et al., 2007), there are few studies of this dietary manipulation on the brains of offspring at or before weaning. With one report showing an increase in circulating TG levels in newborn offspring from dams on a fat-rich diet (Guo and Jen, 1995), it is interesting that high-fat diet exposure during pregnancy and lactation can stimulate the expression in weanling rats of PVN GAL and PFLH ORX, but not NPY in the ARC (Kozak et al., 1998; Beck et al., 2006).

In the present study, we investigated the effects of in utero high-fat diet exposure on the development of the different fatsensitive peptide systems in the PVN and PFLH and their pattern of expression postnatally in the absence of the diet. We identified neuroepithelium of the hypothalamic third ventricle as a target site of the maternal diet and demonstrated a profound effect of the high-fat diet during gestation on the proliferation and differentiation of neurons which ultimately express these specific, fatresponsive peptides that stimulate consumption of this diet.

\section{Materials and Methods}

Animals. Time-pregnant, Sprague Dawley rats (220-240 g) from Charles River Breeding Laboratories were delivered to the animal facility on embryonic day 5 (E5). The dams were individually housed in plastic cages, in a fully accredited AAALAC facility $\left(22^{\circ} \mathrm{C}\right.$, with a $12: 12 \mathrm{~h}$ light-dark cycle with lights off at 2 P.M.), according to institutionally approved protocols as specified in the NIH Guide to the Use and Care of Animals and also with approval of the Rockefeller University Animal Care Committee. The rats were maintained ad libitum from E6 (one experiment from E9) on either a high-fat diet (HFD) with $50 \%$ fat or a balanced, control diet (BD) with $25 \%$ fat (see below). Standard lab chow was available for 3 additional days (until E9), while the dams became fully adapted to the mixed diet and consumed little chow. Over the course of the experiments, food intake was measured 3 times per week, and body weight was recorded weekly. The HFD compared with the BD had no impact on the dams' daily caloric intake during pregnancy (70-90 kcal) and lactation (100$125 \mathrm{kcal})$ or on their body weight at parturition $(320-350 \mathrm{~g})$.

The litters of the HFD dams were similar to the BD litters in terms of size, body length, body weight, and female/male ratio, with no spontaneous abortions observed in either diet group. With half of the HFD litters cross-fostered to BD dams at birth, a third group of offspring referred to as HFD-BD was tested. Whereas the offspring of the BD and HFD dams were suckled by their own dams and maintained on their respective diets until they were killed at different postnatal ages, the HFD-BD offspring were removed from their HFD dam at birth and suckled by a BD dam that had no prior exposure to the HFD. On postnatal day 2 (P2), litters studied after birth were culled to $n=8$, primarily by eliminating the females. Each experiment (except for the first one) tested only male offspring, with 1 male pup taken from each litter and the number of rats/group (generally $n=4-6$ ) equal to the number of litters. The BD, HFD, and HFD-BD offspring were killed at different postnatal ages by rapid decapitation, and whole-brain or dissected-brain tissue along with trunk blood was collected for further analyses.

For the behavioral and physiological experiments, both male and female offspring in the BD, HFD, and HFD-BD groups ( $n=6-8$ /group) were examined from weaning (day 21) until $70 \mathrm{~d}$ of age (D70), a few weeks after puberty. During this time, all rats were maintained on the BD, except for the period from D50 to D60, when they were given access to both the BD and HFD. Frequent measurements (every 3-4 d) were taken of body weight and $24 \mathrm{~h}$ caloric intake, as well as the rats' preference for fat or carbohydrate ( $\%$ of total caloric intake) that was calculated from the intake data obtained when the rats had both diets available. In addition, the female rats after weaning were inspected daily to determine the day of vaginal opening. At D70, all rats were killed, and trunk blood and brains were collected for further analyses. Unilateral body fat from 3 regions (gonadal, retroperitoneal, and inguinal tissue) and the mesen- teric fat pad were dissected and weighed, with the body fat measure reflecting the sum of the 4 individual fat pads.

Diets. The constituents of the HFD (5.15 kcal/g) and BD (4.29 kcal/g), described in detail previously (Dourmashkin et al., 2006), were as follows. The BD was composed of $25 \%$ fat, consisting of $70 \%$ lard (Armour) and $30 \%$ vegetable oil (Wesson), and of $50 \%$ carbohydrate, consisting of $30 \%$ dextrin (MP Biomedicals), 30\% cornstarch (VWR International), and $40 \%$ sucrose (Domino). The HFD was composed of $50 \%$ fat, consisting of $80 \%$ lard and $20 \%$ vegetable oil, and of $25 \%$ carbohydrate, consisting of $30 \%$ dextrin, $30 \%$ cornstarch, and $40 \%$ sucrose. Both diets contained 25\% protein, composed of casein (Bioserv) with $0.3 \%$ L-cystine and DL-methionine (MP Biomedicals), and were supplemented with 4\% minerals (Briggs N Salt Mixture, MP Biomedicals) and 3\% vitamins (Vitamin Diet Fortification Mixture, MP Biomedicals). These diets are nutritionally complete and found to have no detrimental effects on the health of the animals.

Brain dissections. Immediately after sacrifice, the postnatal brain was placed in a matrix with the ventral surface facing up, and three $0.5 \mathrm{~mm}$ coronal sections were made, with the middle optic chiasma as the anterior boundary. Three hypothalamic areas, the PVN at the level of bregma A 3.8-3.5 mm and the PFLH and ARC at bregma A 2.9-2.3 mm, were rapidly microdissected under a microscope using the fornix and third ventricle as landmarks and the stereotaxic atlas of a 10-d-old rat brain for guidance (Sherwood and Timiras, 1970). The PVN was dissected as a reversed isosceles triangle, $0.5 \mathrm{~mm}$ bilateral to the ventricle and between the fornix structures. For the PFLH, the dissection was taken from the area surrounding the fornix, within a range of $0.1 \mathrm{~mm}$ medial and ventral to the fornix, $0.2 \mathrm{~mm}$ dorsal, and $0.1 \mathrm{~mm}$ lateral. For the ARC, the area adjacent to the bottom of the third ventricle was dissected parallel to the border of the ventricle, with the width of $0.1 \mathrm{~mm}$ at the top gradually widening to $0.2 \mathrm{~mm}$ at the bottom. These dissections were immediately frozen in liquid nitrogen and stored at $-80^{\circ} \mathrm{C}$ until processed.

Real-time quantitative PCR analysis. Real-time quantitative PCR was used to measure mRNA levels in the PVN, PFLH, or ARC of 7 peptides in the BD, HFD, and HFD-BD offspring at P15 ( $n=4-6$ /group). These peptides included GAL, ENK, and DYN expressed in the PVN and ARC, NPY and AgRP in the ARC, ORX in the PFLH, and melaninconcentrating hormone $(\mathrm{MCH})$ in the PFLH, which may also show some increase after consumption of a HFD (Kennedy et al., 2007). As previously described (Chang et al., 2004), total RNA from pooled microdissected hypothalamic samples $(n=10)$ was extracted with Trizol reagent and treated with RNase-free DNase 1. The cDNA and minus RT were synthesized using an oligo-dT primer with or without SuperScript II reverse transcriptase. The real-time quantitative PCR was conducted with Applied Biosystems (ABI) system. With Applied Biosystems Primer Express V1.5a software, primers were designed to have a melting temperature of $58-60^{\circ} \mathrm{C}$ and to produce an amplicon of $50-160 \mathrm{bp}$. The last five bases on the $3^{\prime}$ end contained no more than $2 \mathrm{G}$ and/or $\mathrm{C}$ bases, to reduce the possibility of nonspecific product formation. The sequences of primers are shown in supplemental Table $1 A$ (available at www.jneurosci.org as supplemental material).

The SYBR Green PCR core reagents kit (ABI) was used with $\beta$-actin as an endogenous control. We also tested 2 other housekeeping genes, cyclophilin and GAPDH, and found each of these to yield consistent expression patterns across tissues and experimental paradigms and show similar trends in the results across groups. We chose $\beta$-actin, however, because it yielded the smallest variation in the different brain areas tested. PCR was performed in MicroAmp Optic 96-well Reaction Plates (ABI) on an ABI PRISM 7900 Sequence Detection system, with the condition of $2 \mathrm{~min}$ at $50^{\circ} \mathrm{C}, 10 \mathrm{~min}$ at $95^{\circ} \mathrm{C}$, then 40 cycles of $15 \mathrm{~s}$ at $95^{\circ} \mathrm{C}$ and $1 \mathrm{~min}$ at $60^{\circ} \mathrm{C}$. Each study consisted of 4 independent runs of PCR in triplicate, and each run included a standard curve, nontemplate control, and negative RT control. The levels of target gene expression were quantified relative to the level of $\beta$-actin by standard curve method, based on threshold with Ct value of 18-25 for the different genes. The concentrations of primers were $100-200 \mathrm{~nm}$, and all reagents, unless indicated, were from Invitrogen. The specificities of RT-PCR products were confirmed by both a single dissociation curve of the product and a single band with a corresponding molecular weight revealed by an agarose gel 
A
Body Weight

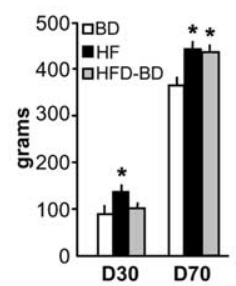

Caloric Intake

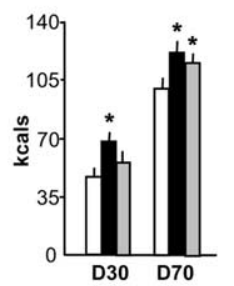

\%Fat \%Carb

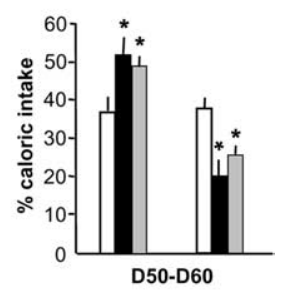

B

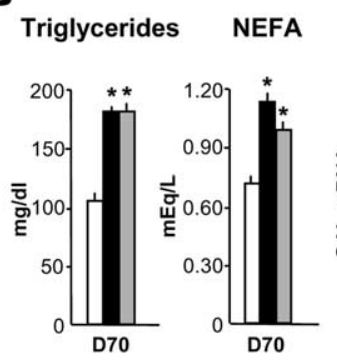

C

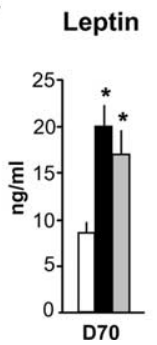

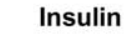

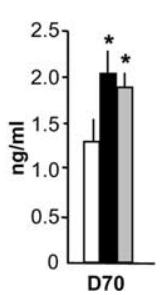

PVN Galanin
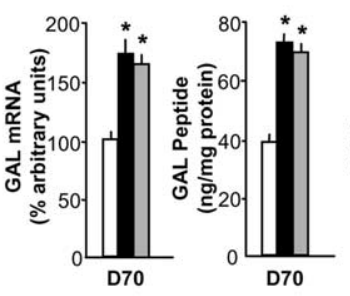

Body fat

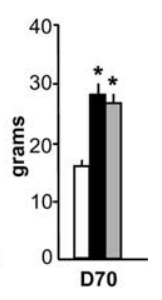

NPY
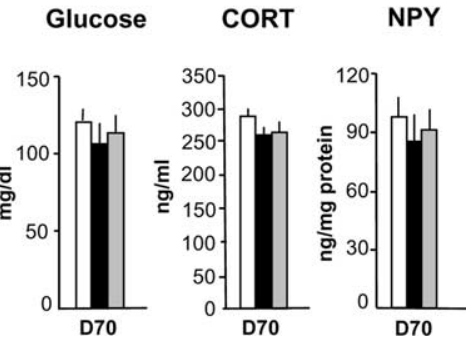

Figure 1. Prenatal HFD in both the HFD and HFD-BD groups compared with the BD group ( $n=6-8$ /diet group) produced behavioral, physiological, and neurochemical changes (mean \pm SEM) in the male offspring after weaning, as indicated by a significant increase $\left({ }^{*} p<\right.$ 0.05) in measures of body weight or daily caloric intake on day 30 (D30) and day 70 (D70) and of preference (\% of total diet) for fat versus carbohydrate on D50-D60 $(\boldsymbol{A})$; triglyceride, NEFA, galanin $\mathrm{mRNA}$, and peptide levels in the PVN, and body fat pad weights on D70 (B); and leptin and insulin levels, with no change in glucose, CORT, and NPY on D70 (C).

electrophoresis. In addition to the nontemplate control and a negative RT control, the specificity of the quantitative PCR was verified with an anatomical negative control by using the corpus callosum in the same brain. No signals above threshold of all 7 targeted genes were detected by quantitative PCR in all of the controls.

Radiolabeled in situ hybridization histochemistry. The mRNA levels of GAL, ENK, DYN, ORX, and MCH were also measured by radiolabeled in situ hybridization histochemistry in the BD, HFD, and HFD-BD offspring at P15 ( $n=4-6 /$ group). The pups were killed by rapid decapitation, and the brains were immediately removed and fixed in $4 \%$ paraformaldehyde $\mathrm{PB}(0.1 \mathrm{M}, \mathrm{pH} 7.2)$ for $48-72 \mathrm{~h}$, cryoprotected in $25 \%$ sucrose for $48-72 \mathrm{~h}$, and then frozen and stored at $-80^{\circ} \mathrm{C}$. The antisense and sense RNA probes were labeled with ${ }^{35} \mathrm{~S}$-UTP (Amersham Biosciences) as described previously (Leibowitz et al., 1998; Lucas et al., 1998; Tritos et al., 1998; Wortley et al., 2003). Free-floating $30 \mu \mathrm{m}$ coronal sections were processed as follows: $10 \mathrm{~min}$ in $0.001 \%$ proteinase $\mathrm{K}, 5 \mathrm{~min}$ in $4 \%$ paraformaldehyde, and $10 \mathrm{~min}$ each in $0.2 \mathrm{~N} \mathrm{HCl}$ and acetylation solution, with 10 min wash in $\mathrm{PB}$ between each step. After washing, the sections were hybridized with ${ }^{35}$ S-labeled probe $\left(10^{3} \mathrm{cpm} / \mathrm{ml}\right)$ at $55^{\circ} \mathrm{C}$ for $18 \mathrm{~h}$. After hybridization, the sections were washed in $4 \times$ SSC, and nonspecifically bound probe was removed by RNase (Sigma) treatment for 30 $\min$ at $37^{\circ} \mathrm{C}$. Then, sections were run through a series of stringency washes with $0.1 \mathrm{M}$ dithiothreitol (Sigma) in $2 \times$ SSC and $1 \times$ SSC and $0.1 \times \mathrm{SSC}$ at $55^{\circ} \mathrm{C}$. Finally, sections were mounted, air dried, and exposed to Kodak BioMax MR film for $8-18 \mathrm{~h}$ at $-80^{\circ} \mathrm{C}$, developed, and microscopically analyzed. The sense probe control was performed in the same tissue, and no signal was found.
Gene expression level was determined with a computer-assisted microdensitometry of autoradiographic images on the MCID image analysis system (Image Research) as described previously (Lucas et al., 1998; Reagan et al., 2004). Microscale ${ }^{14} \mathrm{C}$ standards (Amersham Biosciences) were exposed on the same Kodak film with the sections and digitized. Gray level/optical density calibrations were performed by using a calibrated film strip ladder (Imaging Research) for optical density. Optical density was plotted as a function of microscale calibration values. It was determined that all subsequent optical density values of digitized autoradiographic images fell within the linear range of the function. The values obtained represent the average of measurements taken from 10-12 sections per animal. In each section, the optical density for the PVN, PFLH, and ARC was recorded, from which the background optical density from a same size area in the thalamus was subtracted. The mean value of the HFD and HFD-BD groups in each experiment was reported as percentage of the $\mathrm{BD}$ group.

Digoxigenin-labeled in situ hybridization histochemistry. For better visualization, in situ hybridization histochemistry with a digoxigeninlabeled probe was performed, as described above, to reveal the anatomical distribution of changes in peptide expression in the BD and HFD offspring ( $n=4-6 /$ group) at birth. AP-conjugated sheep antidigoxigenin fragments (1:1000, Roche) and NBT/BCIP (Roche) were used to visualize the signal, and sections were dehydrated and coverslipped for semiquantitation, as described previously (Leibowitz et al., 2007).

5-Bromo-2-deoxyuridine immunocytochemistry. To label proliferating cells in the hypothalamus of the embryo, the BD and HFD dams were given intraperitoneal (i.p.) injections of 5-bromo-2-deoxyuridine $(\mathrm{BrdU})(20 \mathrm{mg} / \mathrm{kg}$, Sigma) in $0.9 \% \mathrm{NaCl}$ and $0.007 \mathrm{~N} \mathrm{NaOH}$ every $8 \mathrm{~h}$ from E11 to E13, E13 to E14, or E14 to E15, the period of peak cell birth in rat hypothalamus (Ifft, 1972; Altman and Bayer, 1978; Markakis and Swanson, 1997; Markakis, 2002). The offspring ( $n=4-6 /$ age/group) were killed at different postnatal ages (P0, P8, P15, and P21), and their brains were removed and processed as described above for radiolabeled in situ hybridization histochemistry. To label neuroepithelial, precursor, and migrating cells in the embryonic hypothalamus, the dams at E14 were given one injection of $\mathrm{BrdU}$ ( $160 \mathrm{mg} / \mathrm{kg}$, i.p.), and the fetuses were removed $3 \mathrm{~h}$ later. The embryonic brain was removed and processed as described above.

For BrdU immunocytochemistry, 30-40 $\mu \mathrm{m}$ free-floating coronal sections were treated with $0.2 \mathrm{~N} \mathrm{HCl}$ for $60 \mathrm{~min}$ at $37^{\circ} \mathrm{C}$, then consecutively processed at room temperature as follows: $30 \mathrm{~min}$ in $0.1 \mathrm{M}, \mathrm{pH} 8.5$, borate buffer, $10 \mathrm{~min}$ in PBS, $60 \mathrm{~min}$ in 5\% normal rabbit serum containing $0.5 \%$ Triton X-100 PBS, overnight in rat anti-BrdU monoclonal antibody (1:1000, Novus Biologicals), 30 min wash in PBS, 2 h incubation in biotinylated rabbit anti-rat IgG (1:200, Vector Laboratories), 30 min wash in PBS, and $2 \mathrm{~h}$ incubation in ABC (1:300, Vector Laboratories). After $30 \mathrm{~min}$ rinse in $\mathrm{PBS}, \mathrm{BrdU}$ immunoreactivity was revealed with $\mathrm{H}_{2} \mathrm{O}_{2} / \mathrm{DAB}$ (Sigma). After the wash in PBS, sections were mounted, dehydrated, and coverslipped for quantitative analysis (see below, Semiquantification of digoxigenin-labeled in situ hybridization and immunohistochemistry). Specific controls were performed with sections that omitted the rat anti-BrdU antibody or were from non-BrdU-injected animals, both of which showed no BrdU-immunoreactive staining.

Immunofluorescence histochemistry. Single- and double-immunofluorescence staining was used to label postnatal or embryonic brain tissue. The postnatal tissue was examined at P8 and P15 in most experiments, except for those measuring double labeling of BrdU with ORX or $\mathrm{MCH}$, which examined somewhat older, P21, offspring to obtain better peptide immunofluorescence. For labeling of BrdU, the tissue was processed in the same manner as described for BrdU immunocytochemistry above. For all single labeling, after incubation in primary antibody, sections were rinsed for $30 \mathrm{~min}$ in PBS and then were incubated in properly conjugated secondary antibody for $2 \mathrm{~h}$. After rinsing in PBS for $10 \mathrm{~min}$, the sections were mounted and coverslipped with Vectashield mounting medium (Vector Laboratories). For double labeling using BrdU, the tissue was first treated with $\mathrm{HCl}$ as described for BrdU immunocytochemistry, and then processed following the single-labeling procedure. Information on the antibodies and protocols for single- and double-labeling immunofluorescence is provided in supplemental Table $1, B$ and $C$ (available at 
www.jneurosci.org as supplemental material), and all procedures were performed at room temperature. Fluorescence image was captured with a Zeiss fluorescence microscope with MateVue software. Density of immunofluorescence objects was quantified with ImagePro software as described below and reported as density (objects/ $\mu \mathrm{m}^{2}$ ). Double-labeled cells were counted and reported as percentage of total single-labeled cells.

Double labeling of digoxigenin in situ hybridization of peptide with BrdU immunofluorescence histochemistry. Digoxigenin in situ hybridization of peptides, GAL, ENK, and DYN, in combination with BrdU immunofluorescence histochemistry was used to determine whether BrdU-labeled cells express these specific peptides. The P8 brains of BD, HFD, and HFD-BD offspring ( $n=4-6$ /group) of dams with BrdU injections from E11-13 were cut, and three sets of $30 \mu \mathrm{m}$ free-floating alternative coronal sections were processed for digoxigenin in situ hybridization (see above). After the signal was visualized in NBT/BCIP, sections were briefly washed in $0.1 \mathrm{M}$ Tris- $\mathrm{HCl}$ containing $0.1 \mathrm{M} \mathrm{NaCl}$ and $50 \mathrm{mM} \mathrm{MgCl}_{2}, \mathrm{pH} 9.5$, and PBS, and then were treated in $0.2 \mathrm{~N} \mathrm{HCl}$ for $60 \mathrm{~min}$ at $37^{\circ} \mathrm{C}$. Afterward, sections were processed for BrdU immunofluorescence and viewed on a Zeiss microscope with MateVue software. Peptide-expressing neurons with dark-blue digoxigenin-labeled signal were viewed and captured with DIC filter first, and then the red Texas Red/Cy3 fluorescence filter was applied to reveal the BrdU-positive signal in the same field. The images were merged, and double-labeled cells were counted and expressed as percentage of total single-labeled cells.

Semiquantification of digoxigenin-labeled in situ hybridization and immunohistochemistry. Semiquantification of cell density of GAL-, ENK-, DYN-, ORX-, and MCH-expressing neurons, BrdU-immunoreactive cells from DAB reaction, and immunofluorescence cells or fiber density of BrdU, NeuN, Dcx, Tuj1, nestin, or vimentin were performed as described previously (Leibowitz et al., 2007). Briefly, sections were viewed on a Leitz microscope ( $10 \times$ objective). The images were captured with a Nikon DXM 1200 digital camera (Nikon) and analyzed using ImagePro Plus software (version 4.5, Media Cybernetics) on a gray-value scale from 1 to 255 . In each animal, $8-10$ sections at the same level were used to examine each nucleus or area of interest, and the entire nucleus or area was outlined and analyzed. The population density was used to determine the cell or fiber density in these areas. Before measurements, a threshold for each nucleus or area was established. Using the selected sections, this threshold was set by matching the number of objects counted by the software in a defined area with the number of objects counted manually in that same area. This method, which was the same for all experiments and brain areas, yielded different threshold values (average of thresholds obtained within the same area in the 10 sections) for the different brain areas, experiments, and measurements of cells versus fibers. This semiquantitative procedure allowed one to count the number of neurons or fibers in a specific area, which were then expressed as the cell density (number of cells/ $\mu \mathrm{m}^{2}$ ) or object density (number of fibers $/ \mu \mathrm{m}^{2}$ ), respectively. The average cell or object density for the different groups was then compared and statistically analyzed, with the analyses performed by an observer unaware of the identity of the animals.

Radioimmunoassay. The PVN tissue, dissected from the BD, HFD, and HFD-BD offspring at P8 and P15 ( $n=4-6$ /age/diet group), was homogenized in $1 \mathrm{ml}$ of $0.1 \mathrm{M}$ acetic acid and centrifuged at $14,000 \times \mathrm{g}$ for $15 \mathrm{~min}$ at $4^{\circ} \mathrm{C}$. All of the supernatant was removed, boiled for $10 \mathrm{~min}$, and frozen at $-80^{\circ} \mathrm{C}$ until use. For radioimmunoassay (RIA), GAL and NPY were measured as described previously (Akabayashi et al., 1994b; Leibowitz et al., 1998), and met-ENK and DYN-A were measured using commercially available kits (Peninsula Laboratories).

Hormone and metabolite assays. Serum from trunk blood of BD, HFD, and HFD-BD offspring and dams was assayed using commercially available radioimmunoassay kits for insulin and leptin (Linco Research) and corticosterone (MP Biomedicals). Serum TG and glucose levels were assayed using a Triglyceride Assay kit from Sigma or glucose kit from TECO Diagnostics, respectively. Nonesterified fatty acids (NEFAs) were assayed in serum using a kit from WAKO Pure Chemical Industries.

Statistical analysis. The values in the figures and tables are expressed as mean \pm SEM. In each experiment, a direct comparison between the scores for a pair of groups was made using an unpaired
A
PVN

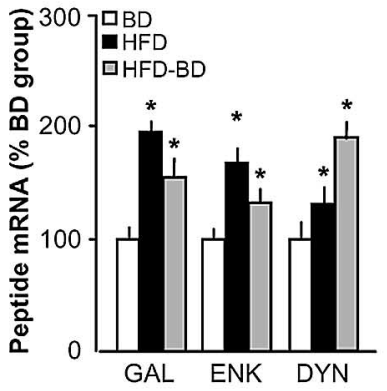

PFLH

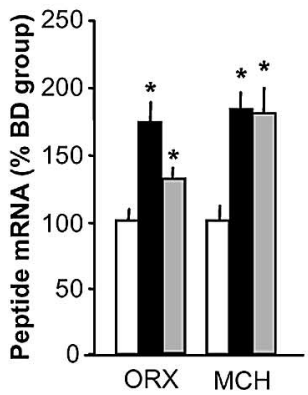

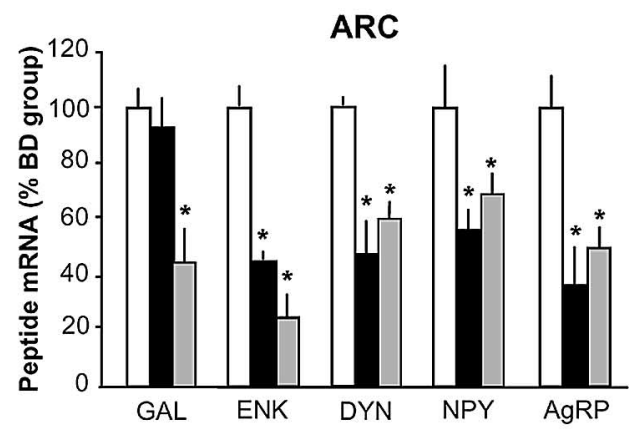

B

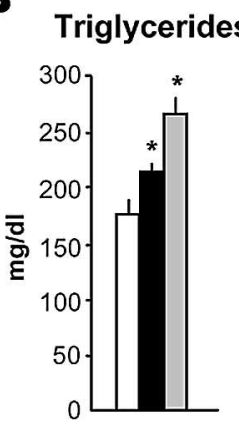

Body Weight

Leptin
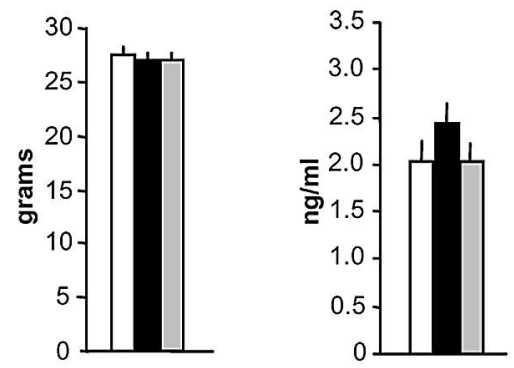

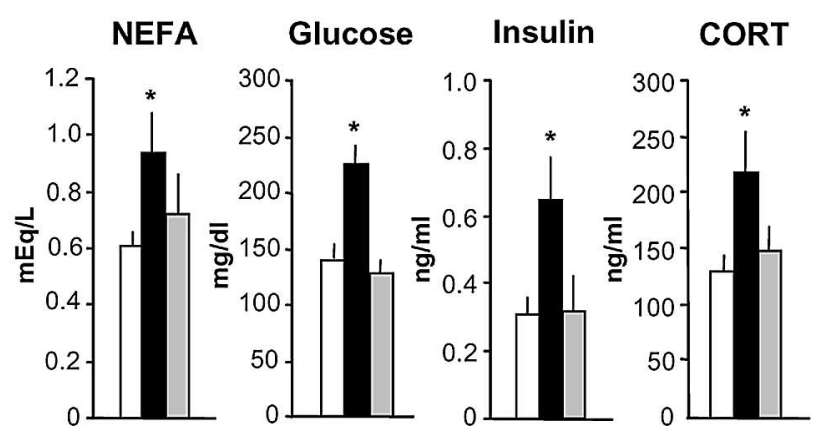

Figure 2. Prenatal HFD in both the HFD and HFD-BD groups compared with the BD group $(n=$ 4-6/age/diet group) produced changes in gene expression (mean \pm SD) of orexigenic peptides in the PVN and PFLH on postnatal day 15 (P15), as measured by real-time quantitative PCR. This is indicated by a significant increase $\left({ }^{*} p<0.05\right)$ in both prenatal HFD groups of GAL, ENK, and DYN mRNA levels in the PVN and ORX and MCH mRNA in the PFLH, along with a decrease in peptide $m R N A$ in the $\operatorname{ARC}(\boldsymbol{A})$; and circulating levels of triglycerides, with no change in body weight or leptin and increased levels only in the HFD group of NEFA, glucose, insulin, and CORT (B).

Student's $t$ test. With multiple comparisons, data were analyzed by one-way ANOVA, with a Bonferroni post hoc test to determine significant differences between the groups. The criterion for statistical significance was $p<0.05$. 
A
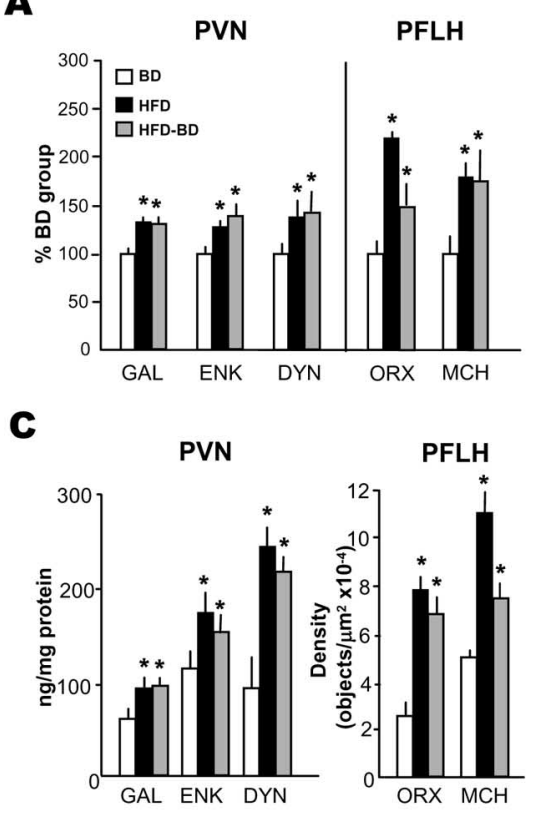

PVN

B
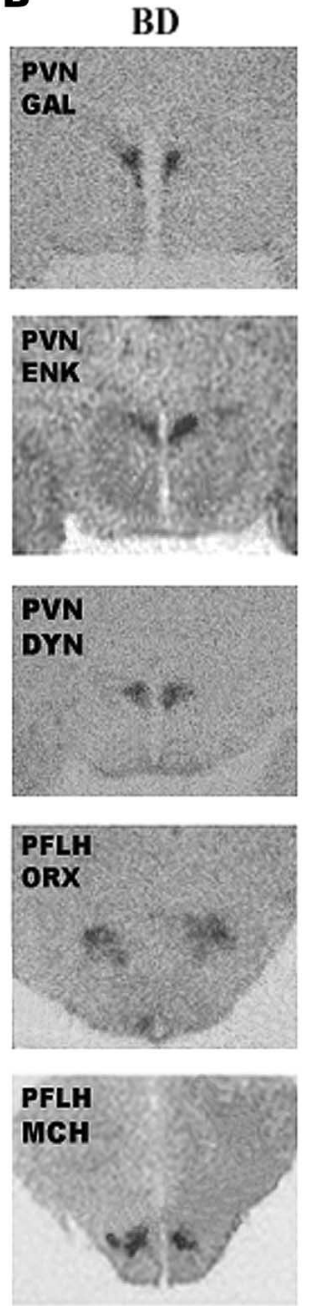

HFD-BD
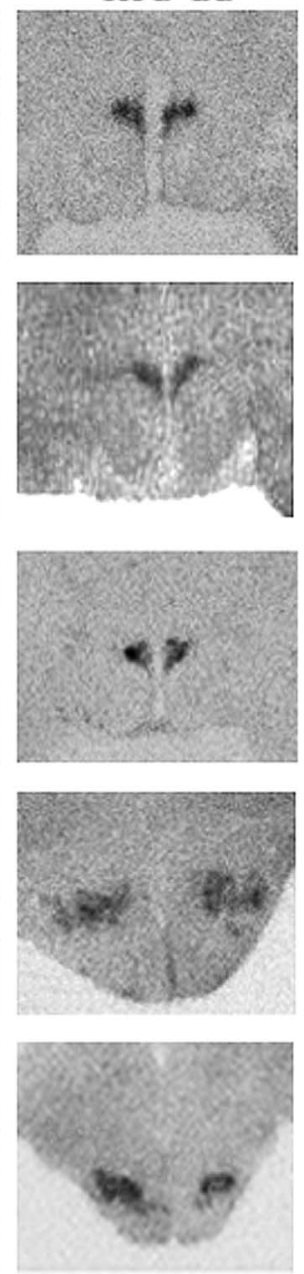

Figure 3. Prenatal HFD in both the HFD and HFD-BD groups compared with the BD group ( $n=4-6 /$ diet group) produced changes in the orexigenic peptides (mean $\pm S D$ ) in the PVN and PFLH of postnatal offspring, as measured by different techniques. This is indicated by a significant increase $\left({ }^{*} p<0.05\right.$ ) in mRNA levels (\% of BD group) of GAL, ENK, and DYN in the PVN and ORX and $\mathrm{MCH}$ in the PFLH at P15, as measured by radiolabeled in situ hybridization with ${ }^{35} \mathrm{~S}$-labeled probes $(\boldsymbol{A})$; photomicrographs illustrating this effect in the PVN and PFLH of the HFD-BD offspring compared with the BD $(\boldsymbol{B})$; and a significant increase $\left({ }^{*} p<\right.$ 0.05 ) in peptide levels in the PVN, as measured by radioimmunoassay in P15 offspring, or in the PFLH, as measured by immunofluorescence in P21 offspring (C).

\section{Results}

\section{Long-term changes in adult offspring induced by prenatal} HFD exposure

Building on prior studies showing long-term, physiological effects of HFD exposure extending through both pregnancy and lactation (see Introduction), we examined the effects of a shorter period of exposure to a HFD, 2 weeks prenatally (E6-P0) or postnatally (P1-P15). Also, rather than using a low-fat diet $(10 \%$ fat) as a control, we compared this HFD ( $50 \%$ fat) to a more balanced, moderate-fat diet (BD), which is closer in fat content (25\% fat) and thus minimizes any group differences in caloric intake and body weight. This experiment had 4 sets of dams that produced 4 groups of offspring, as described in the Materials and Methods section. They were the (1) BD group, which was maintained on a BD both prenatally and postnatally; (2) HFD group, which had a HFD both prenatally and postnatally; (3) HFD-BD group, which had the HFD only prenatally and the BD postnatally, with the offspring cross-fostered at birth to BD dams never previously exposed to a HFD; and (4) BD-HFD group, which had the BD prenatally and HFD only during the postnatal period. Compared with the $\mathrm{BD}$ group, the two groups with prenatal HFD exposure, whether the HFD continued postnatally until weaning (HFD group) or was removed at birth (HFD-BD group), exhibited similar behavioral, physiological, and neurochemical changes that persisted after weaning (P21) in the absence of the HFD, as illustrated for male offspring (Fig. 1). Although only the HFD offspring exhibited an increase in body weight and daily caloric intake at $30 \mathrm{~d}$ of age (D30), both the HFD and HFD-BD male groups showed these effects after puberty, as indicated by the D70 measures, and exhibited an enhanced preference for dietary fat when a choice of the two diets was provided from D50 to D60 (Fig. 1A). Further, when examined at D70, the HFD and HFD-BD offspring had increased serum levels of TG and NEFA, elevated GAL mRNA and peptide levels in the PVN, and greater body fat accrual (Fig. $1 B$ ). These changes were accompanied by an increase in leptin and insulin, but no change in serum levels of glucose or CORT and in NPY levels in the ARC (Fig. 1C). Similar effects were observed in the female HFD and HFD-BD offspring (supplemental Table 2, available at www.jneurosci.org as supplemental material), which showed an even greater percentage increase $(p<0.05)$ compared with males in their body fat $(+140 \%$ vs $+75 \%)$ and leptin levels $(+240 \%$ vs $+150 \%)$ and reached puberty (day of vaginal opening) at an earlier age (days 29-32) compared with the BD offspring (days 33-36). These changes in adult rats were not evident in the BD-HFD group, which was exposed for 2 weeks (P1-P15) to the HFD only during the postnatal period (data not shown). These findings underscore the importance of in utero exposure to the HFD. They show it to be sufficient to produce long-term effects, even compared with a moderate-fat BD, that persist after birth and weaning in the absence of the HFD.

\section{Changes in preweanling offspring induced by prenatal HFD exposure}

This experiment examined whether prenatal HFD exposure affects gene expression in preweanling offspring, similar to adults (see Introduction), of different orexigenic peptides that may contribute to their long-term changes in eating patterns. With dams placed on the HFD or BD at E6, 3 groups of offspring, BD, HFD, and HFD-BD, were formed and then killed before weaning, at $15 \mathrm{~d}$ of age (P15), just before the start of independent feeding. While having no impact on the body weight of the dams (320$350 \mathrm{~g}$ ) through gestational day 21, the maternal HFD had a pronounced, site-specific stimulatory effect on the offspring's hypothalamic peptide mRNA, as measured by real-time quantitative PCR (Fig. 2A). At P15, the HFD compared with BD offspring showed increased expression of GAL, ENK, and DYN in the PVN 
and ORX and $\mathrm{MCH}$ in the PFLH. This is in contrast to gene expression in the ARC, which for the 5 peptides examined was unaffected or greatly reduced. This HFDinduced increase in peptide was similarly detected in younger pups at P8, shown with measurements of PVN GAL and PFLH ORX (supplemental Table 3, available at www.jneurosci.org as supplemental material). As demonstrated in adult rats (see Introduction), these peptide changes in the HFD groups were closely associated with an increase in serum levels of TG in both the P8 and P15 offspring; they were dissociated, in contrast, from the measures of body weight and leptin, which remained stable at both ages, and also of NEFA, glucose, insulin, and CORT levels, which were elevated at P15 but not P8 (Fig. 2B; supplemental Table 3, available at www. jneurosci.org as supplemental material). Remarkably, the HFD-BD offspring compared with $\mathrm{BD}$ group showed a similar increase in peptide mRNA, once again, in the PVN and PFLH but not the ARC where gene expression was suppressed (Fig. 2A). This provides the first evidence that a HFD restricted to pregnancy produces changes in the brain that continue well beyond birth and period of diet exposure. Interestingly, in these HFD-BD offspring, the in utero HFD also had effects on circulating TG levels that persisted in the absence of the diet (Fig. 2 B; supplemental Table 3, available at www.jneurosci.org as supplemental material). On the BD after birth, these lipids remained significantly elevated throughout the postnatal period, whereas the other measures of body weight, nutrients, and hormones in the HFD-BD group were unaltered.

These findings, that prenatal HFD exposure has persisting effects on hypothalamic peptide expression, were substantiated in additional sets of postnatal offspring using different techniques. Measurements with radiolabeled in situ hybridization revealed significantly elevated peptide mRNA levels in the HFD and HFD-BD groups compared with BD offspring at P15 (Fig. 3A). These findings are illustrated in photomicrographs of GAL, ENK, and DYN mRNA in the PVN and of ORX and MCH mRNA in the PFLH (Fig. 3B). In accordance with these changes in gene expression, examination of another set of HFD and HFD-BD offspring revealed increased levels of the peptides in the PVN and PFLH, as measured by RIA or immunofluorescence (Fig. 3C). These results, showing clear changes in both mRNA and peptide levels in postnatal pups that had elevated TG similar to Figure $2 B$, demonstrate the profound vulnerability of the offspring to dietary fat during gestation. They reveal marked changes in specific hypothalamic peptide systems controlling feeding and peripheral systems involved in lipid metabolism, which persist long after parturition and perhaps into adulthood and thus may be attributed to phenomena occurring in utero.

\section{Effects of prenatal HFD exposure on the density of neurons at birth}

To visualize possible changes in peptide-expressing neurons at birth, we used digoxigenin-labeled in situ hybridization to examine the offspring of dams maintained on the HFD or BD from E6
B
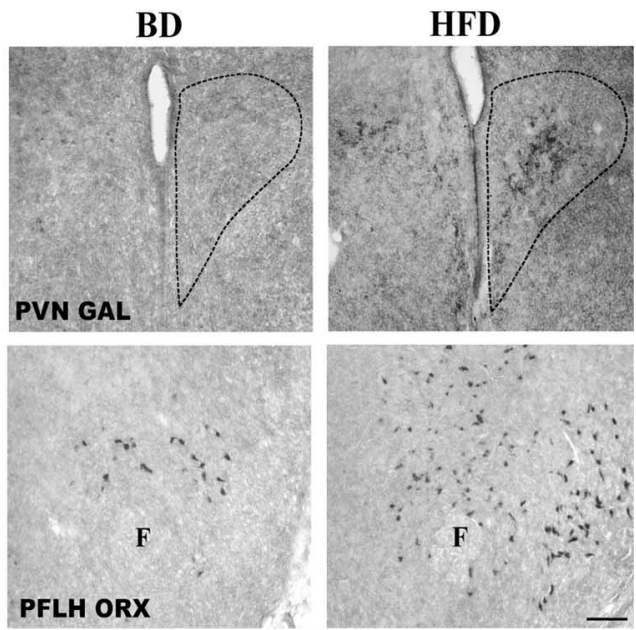

$3.09 \pm 0.12^{*}$

$10.6 \pm 0.16^{*}$

$2.37 \pm 0.09^{*}$

$11.6 \pm 0.39 *$

Figure 4. Prenatal HFD compared with BD offspring ( $n=4-6$ /diet group) produced changes in orexigenic peptide mRNA in the PVN and PFLH at birth (PO), as measured using in situ hybridization with digoxigenin-labeled probes. This is indicated by a and $\mathrm{LH}(\boldsymbol{A})$; and photomicrographs of GAL mRNA in the anterior PVN outlined by a dash line and ORX mRNA in the PFLH just dorsal and lateral to the fornix (F) (scale bar: $100 \mu \mathrm{m})(\boldsymbol{B})$.

to parturition. The BD offspring had very few detectable GALpositive neurons in the PVN at $\mathrm{P} 0$; thus, the impact of the maternal diet on soma density was particularly notable, with the HFD offspring at birth showing a much larger number of PVN GALpositive neurons (Fig. $4 A, B$ ). This effect was site specific, occurring only in the anterior parvocellular region of this nucleus but not in the ARC or dorsomedial nucleus (DMN). The maternal HFD also increased the density of ENK- and DYN-expressing neurons in the PVN at birth, and this effect was evident in the middle-to-posterior region of this nucleus but, once again, not in the ARC, DMN, or ventromedial nucleus (VMN). The peptides expressed in the PFLH were similarly affected by the HFD (Fig. $4 A, B)$. There was an increase in the density of ORX and $\mathrm{MCH}$ neurons, in both the perifornical area dorsal to the fornix (PFH) and the far lateral hypothalamus (LH), as illustrated for ORX. This increased density of neurons at $\mathrm{P} 0$ raises the intriguing possibility that a fat-rich diet creates a particular environment in utero that affects the development of specific neurons in the PVN and PFLH that ultimately express fat-sensitive, orexigenic peptides.

\section{Effects of in utero HFD exposure on cell generation}

To test whether the HFD stimulates the generation of new cells during pregnancy, dams placed on a HFD or BD at E6 were given injections of the cell proliferation marker, BrdU, from E11 to E13, E13 to E14, or E14 to E15. At birth (P0), the offspring from HFD dams that received BrdU injections during these gestational periods exhibited a significant increase in the density of BrdUpositive $\left(\mathrm{BrdU}^{+}\right)$cells in the PVN and PFLH (Fig. $\left.5 A, B\right)$. This is in contrast to the ARC or hippocampus, where no change was observed (supplemental Fig. 1, available at www.jneurosci.org as supplemental material). In additional animals given BrdU injections from E11 to E13, this stimulatory effect on $\mathrm{BrdU}^{+}$cell 
A
PVN

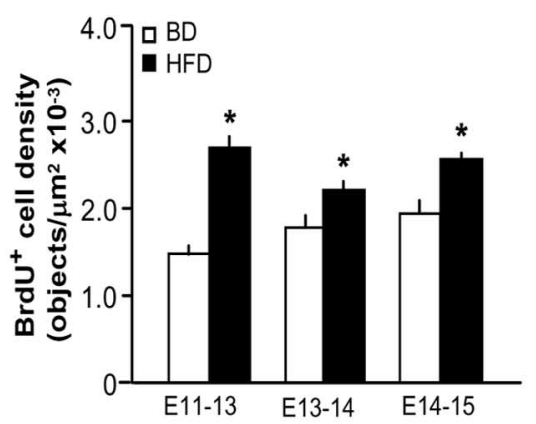

B
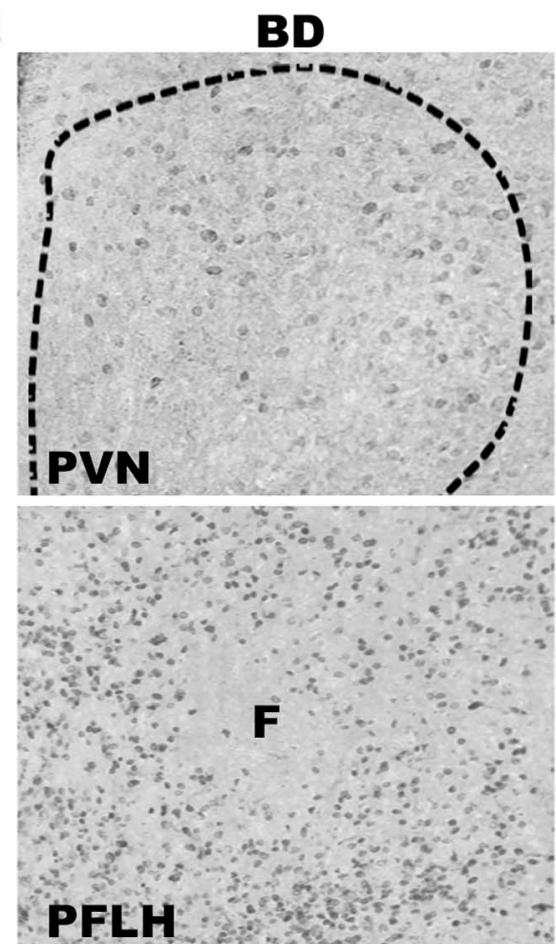

PFLH

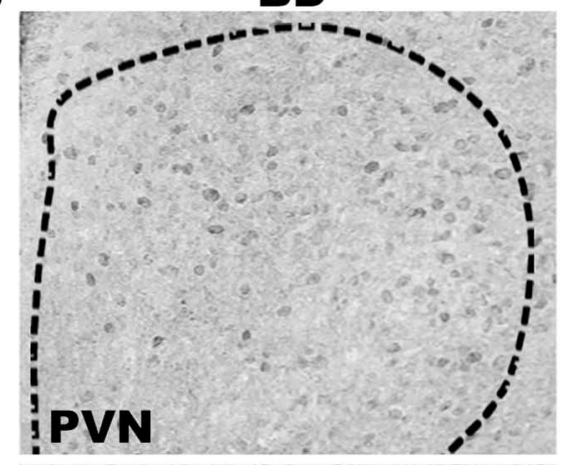

\section{PFLH}

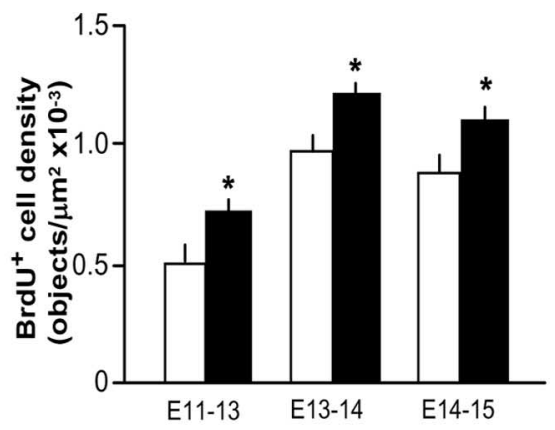

HFD
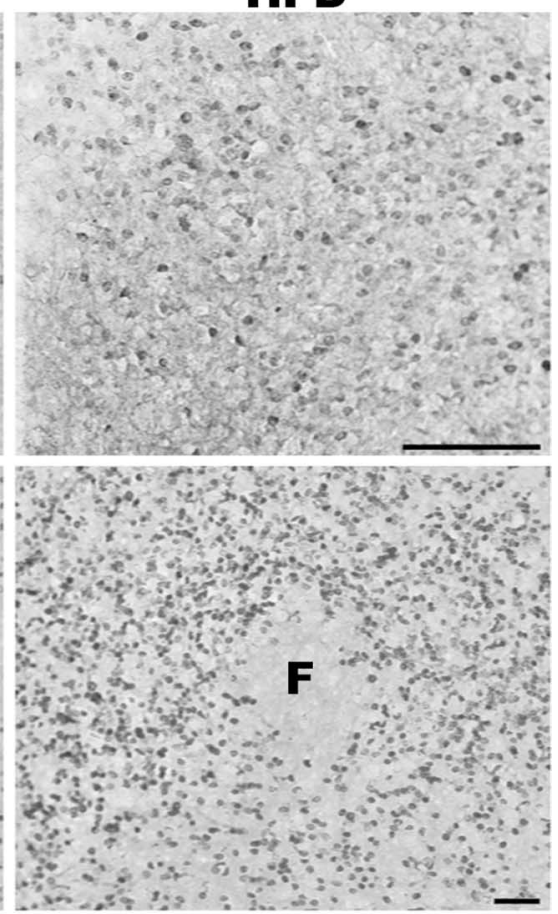

C

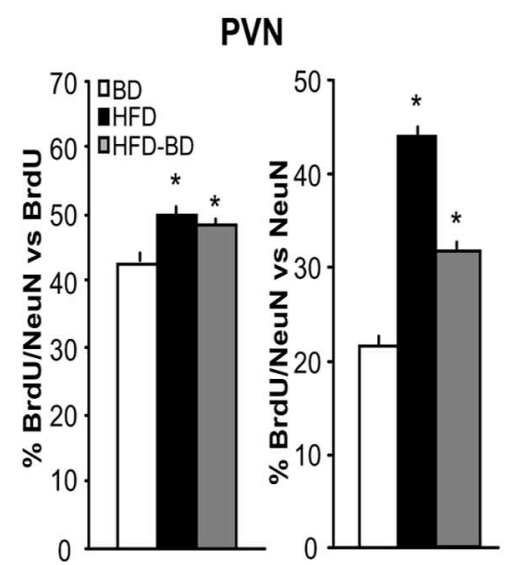

PFLH

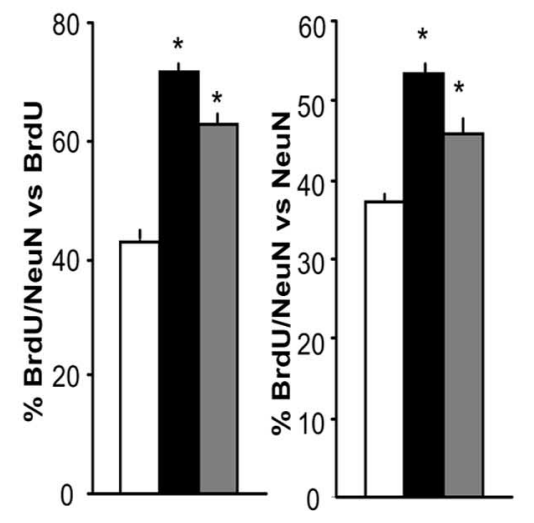

Figure 5. Prenatal HFD stimulated cell proliferation and neurogenesis in the PVN and PFLH of postnatal offspring compared with BD ( $n=4-6$ /diet group). This is indicated by a significant increase $\left({ }^{*} p<0.01\right)$ in BrdU ${ }^{+}$cell density in the PVN and PFLH of the HFD versus $B D$ offspring at $\mathrm{PO}$, from dams receiving i.p. injections of BrdU from E11 to E13, E13 to E14, and E14 to E15 (mean \pm SEM) (A); photomicrographs illustrating BrdU ${ }^{+}$cells in the PVN (dash line) and PFLH around the fornix (F) of P0 offspring $(\boldsymbol{B})$; and a significant increase $\left({ }^{*} p<\right.$ 0.01 ) in double-labeled BrdU ${ }^{+} / \mathrm{NeuN}^{+}$cells in the PVN (scalebar: $100 \mu \mathrm{m}$ ) and PFLH (scale bar: $50 \mu \mathrm{m}$ ) of HFD and HFD-BD offspring at $\mathrm{P} 8$, presented as percentage of double-labeled neurons relative to total single-labeled BrdU ${ }^{+}$cells or NeuN ${ }^{+}$neurons (mean \pm SEM) (C).

density in the PVN and PFLH was similarly evident in the HFD-BD as well as HFD offspring examined at P8 or P15, whether they were initially exposed to the HFD at E6 or as late as E9 (supplemental Fig. 2, available at www.jneurosci.org as supplemental material). These results underscore the robustness of this phenomenon. In multiple groups, they demonstrate an increase in cell generation that is site specific, requires only a few days of in utero HFD exposure, and persists postnatally well beyond the period of diet exposure.

\section{Impact of in utero HFD exposure on neurogenesis}

To investigate the phenotypes of these hypothalamic $\mathrm{BrdU}^{+}$cells, we performed single- or double-labeling immunofluorescence histochemistry using antibodies against NeuN (marker for mature neurons), GFAP (marker for astrocytes), and GalC (marker for oligodendrocytes). With the dams given diets at E6, the HFD and HFD-BD offspring compared with the BD group exhibited a marked increase in colabeling of NeuN with BrdU in the PVN and PFLH at P8 (Fig. 5C). This is indicated in both areas by the increased percentage of double-labeled cells relative to the total single-labeled cells immunoreactive for BrdU or for NeuN. Whereas the glial markers revealed relatively few labeled cells in the PVN and PFLH before P8, there were considerably more at P15 and P25, and the number seen at these ages was unaffected or even slightly reduced in the HFD and HFD-BD offspring (supplemental Fig. 3 , available at www.jneurosci.org as supplemental material). This demonstrates that in utero HFD exposure has its greatest impact on the generation and development of neurons, rather than astrocytes or oligodendrocytes, in these hypothalamic areas.

\section{Phenotype of new neurons generated by} in utero HFD exposure

The next step, using digoxigenin in situ hybridization histochemistry combined with BrdU immunofluorescence or doublelabeling immunofluorescence, was to determine whether these $\mathrm{BrdU}^{+}$neurons affected by the prenatal HFD can express or synthesize the same orexigenic peptides, GAL, ENK, DYN, ORX, and MCH, known to be stimulated by dietary fat in adults. With dams placed on a diet at E6 and given BrdU injections from E11 to E13, the postnatal offspring in the HFD-BD as well as HFD litters exhibited a significant increase in colabeling of BrdU with the different peptides in the PVN and PFLH. This effect, indicated by the increased percentage of 
double-labeled cells relative to the total single-labeled $\mathrm{BrdU}^{+}$or peptide ${ }^{+}$cells, was evident with measurements of GAL, $\mathrm{ENK}$, and DYN in the PVN at P8, as illustrated for GAL (Fig. 6). It was also seen with measurements of ORX and $\mathrm{MCH}$ in the PFLH at P21, as illustrated for ORX which in the BD group exhibited almost no colocalization with BrdU (Fig. 7). These results demonstrate that in utero HFD can stimulate the generation of PVN and PFLH neurons that in postnatal offspring have the specific phenotype of expressing fat-responsive, orexigenic peptides.

\section{Effect of HFD on cell proliferation in embryo's neuroepithelium of hypothalamic third ventricle}

To confirm that a postnatally observed increase in newborn neurons is primarily attributable to an increase in neurogenesis, we focused on a cell analysis of hypothalamic proliferative neuroepithelium (NEP). Neuroepithelium, composed mostly of undifferentiated cells that are multipotent (Qian et al., 2000; Liu et al., 2002; Rao, 2004), is known to differentiate into either neurons or glia depending on environmental as well as cell-intrinsic changes (Yanagisawa et al., 2001). We examined NEP at the level of the hypothalamic third ventricle, specifically the ventral neuroepithelial lobe (VL) (Fig. $8 A$ ), which is an active site for proliferation and differentiation of NEP cells and the source of neurons destined for the PVN and PFLH (Altman and Bayer, 1978). In dams on a HFD or $\mathrm{BD}$ since E6, a single BrdU injection was given at E14, and the embryos were killed $3 \mathrm{~h}$ later. The HFD embryos compared with the BD group exhibited an increase in colabeling of BrdU with NeuN in the proliferative VL and a pronounced thickening of this region (Fig. $8 B, C$ ). This effect, indicating an increase in neuroepithelial cell proliferation and neuronal generation, is shown by the significantly greater percentage of double-labeled cells relative to total single-labeled BrdU- or NeuN-immunoreactive cells in the VL, along with a small increase in the hypothalamus (HYP) adjacent to the NEP. The HFD embryos also exhibited cells in the VL labeled with Dcx, a marker for differentiating and migrating immature neurons, which were barely evident in the BD embryos, and a dramatic increase of this marker in the HYP just outside the NEP (Fig. 9A). Thus, in addition to increased cell proliferation, these results in the embryo demonstrate a stimulatory effect of a HFD in utero on the migration of postmitotic neurons.

\section{Effect of in utero HFD on neuroepithelial cell differentiation into restricted precursor cells}

As a further attempt to distinguish the neurons and glia during early stages of development, we tested in E14 embryos the effect of the prenatal HFD on neuroepithelial restricted precursor cells. The HFD embryos showed a significant increase (Fig. 9B) in the density of $\beta$-tubulin type III ( TuJ1) cells, a marker for neuronalrestricted precursors (NRP) or immature neurons. This was evident in the VL, demonstrating that the HFD stimulated NEP
PVN

PVN

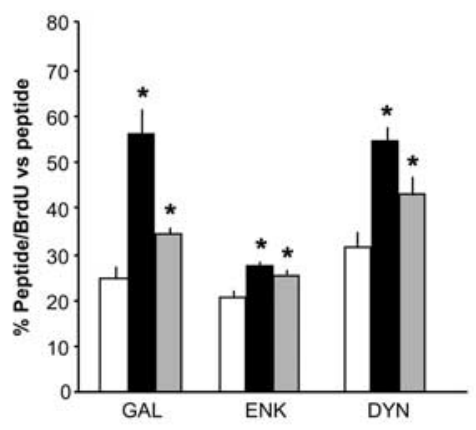

GAL + BrdU

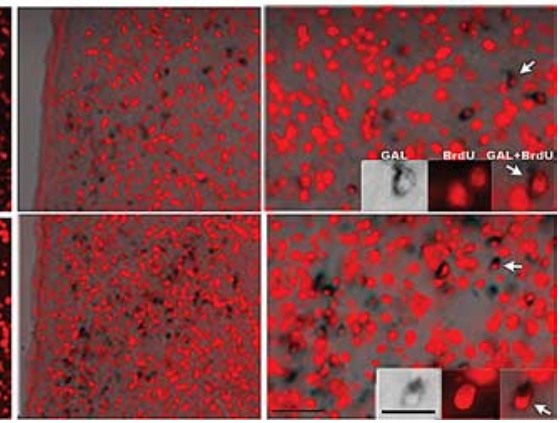

Figure 6. Prenatal HFD increased neurogenesis in the PVN, specifically neurons that express orexigenic peptides. This is shown ce [data (mean + SEM) are expressed as the percentage of double-labeled cells relative to the total single-labeled Brdu ${ }^{+}$ GAL-expressing neurons (back s s examples of double-labeled GAL + BrdU neurons, identified by an arrow.

differentiation into NRP cells, and also in the HYP outside the NEP. In contrast, there was no change in nestin, a marker for glial-restricted precursors at this age, or vimentin, a marker for radial glia and tanycytes (supplemental Fig. 4, available at www. jneurosci.org as supplemental material). These results demonstrate that in utero HFD in E14 embryos acts at the level of the multipotent NEP, stimulating its differentiation specifically into NRP cells. These stimulatory effects of the HFD on cell proliferation and differentiation were accompanied by a marked increase in circulating levels of TG and NEFA in the pregnant dams (E14E18) and also in their offspring at birth (Fig. 9C). In contrast, there was no change in levels of glucose, leptin, insulin, and CORT or in body weight of the dams and newborn pups or in the daily food intake of the dams (supplemental Table 4, available at www.jneurosci.org as supplemental material). This suggests a possible involvement of these circulating lipids in the stimulatory effect of a prenatal HFD on the developing hypothalamus.

\section{Discussion}

It has become increasingly evident that environmental conditions experienced early in life have an important role in the programming of behavioral and physiological systems. Consistent with published reports (Ghosh et al., 2001; Taylor et al., 2005; Férézou-Viala et al., 2007), the present study of perinatal HFD exposure revealed changes in the offspring that became apparent after weaning. With a relatively short period of HFD exposure (2 weeks), male and female offspring of HFD compared with BD dams exhibited after puberty an increase in caloric intake, body weight, leptin, and insulin, a stronger preference for fat, and ele- 
A

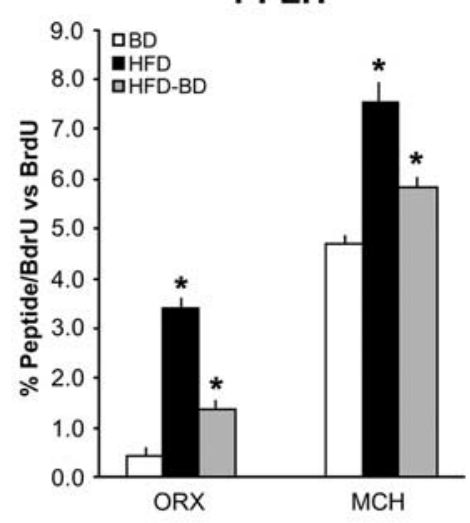

B

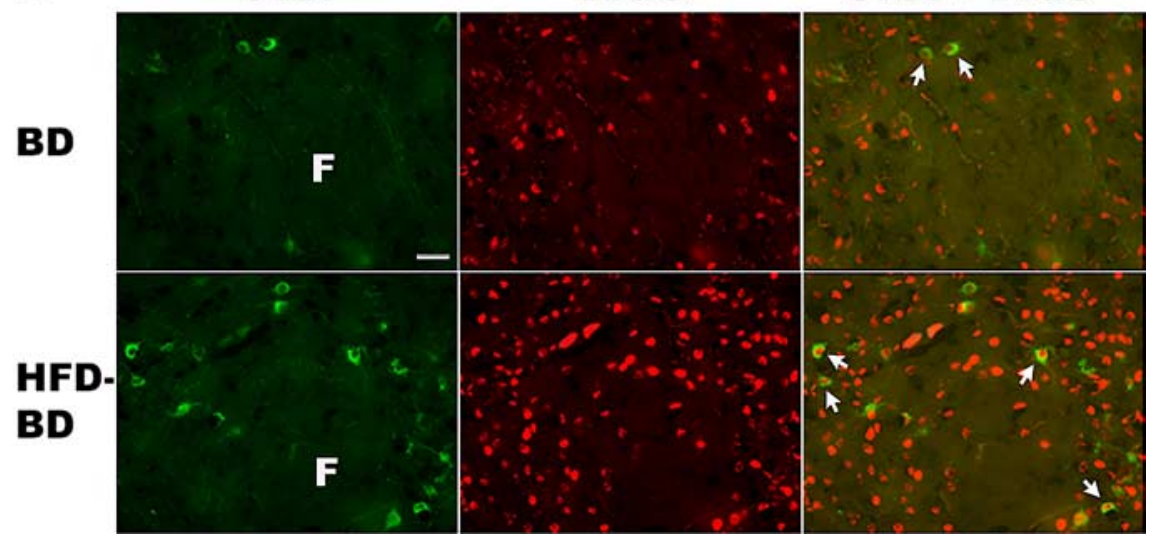

Figure 7. Prenatal HFD increased neurogenesis in the PFLH, specifically neurons that express orexigenic peptides. This is shown by an increase $\left({ }^{*} p<0.01\right)$ in the HFD and HFD-BD versus BD offspring at P21 in double labeling of ORX and MCH peptide with BrdU in PFLH neurons, as revealed by double-labeling immunofluorescence [data (mean \pm SEM) are expressed as the percentage of double-labeled cells relative to the total single-labeled BrdU ${ }^{+}$cells (left) or peptide ${ }^{+}$neurons (right)] (A); and photomicrographs of HFD-BD versus BD P21 offspring illustrating single-labeled ORX-synthesizing neurons (green), single-labeled BrdUimmunoreactive cells (red), and double-labeled $\mathrm{ORX}^{+}+\mathrm{BrdU}^{+}$neurons (green + red) in the PFLH (scale bar: $100 \mu \mathrm{m}$ ), in the area of the fornix (F) (B). Examples of double-labeled neurons are indicated by arrows.

vated TG levels and GAL mRNA and peptide in the PVN. Our finding, that these effects occurred with 2 weeks of in utero HFD exposure but not postnatal HFD, isolated the prenatal period as a critical time in programming PVN GAL neurons in association with enhanced preference for dietary fat and increased weight gain.

Similar to the offspring after puberty, HFD exposure during both the prenatal and postnatal periods stimulated expression of 5 orexigenic peptides in the PVN and PFLH of preweanling offspring. This effect is similar to that described in previous studies of GAL and ORX in weanling rats (Kozak et al., 1998; Beck et al., 2006) and of the 5 peptides in adult rats (Akabayashi et al., 1994a; Welch et al., 1996; Leibowitz et al., 2004; Chang et al., 2007; Kennedy et al., 2007). It is very different, however, from the results obtained in the ARC, where peptides are unaffected or reduced by a HFD and low-protein diets during pregnancy and lactation, while enhanced by undernutrition and gestational diabetes (Kozak et al., 1998; Plagemann et al., 2000; Franke et al., 2005; Beck et al., 2006; Plagemann, 2006). Examination of pups at $\mathrm{P} 8, \mathrm{P} 15$, and $\mathrm{P} 21$ showed that the change in orexigenic peptides in the PVN and PFLH could occur in the absence of any alteration in body weight or leptin and before the start of independent feeding, suggesting that it is transmitted via circulating factors, such as nutrients, that reach the offspring through the dam's milk. With each of the 5 peptides, the increase in mRNA in the PVN and PFLH of HFD offspring was accompanied by a marked increase in peptide levels. This finding supports the possibility that these neurochemical changes have biological significance. Based on pharmacological studies in adult rats (Zhang et al., 1998; Leibowitz, 2000; Clegg et al., 2002; Yun et al., 2005), one would expect their longterm functional consequences to be an increase in food intake and body weight on a fat-rich diet. These effects were observed in the prenatal HFD offspring at $70 \mathrm{~d}$ of age.

Most important were the findings in the HFD-BD offspring cross-fostered at birth to BD dams. These offspring exhibited the same postnatal changes in peptides, demonstrating that they are irreversible by removal of the HFD and thus may be occurring in utero and/or at birth. There are only a few reports examining prenatally manipulated offspring at birth for physiological or peptide effects (Guo and Jen, 1995; Plagemann et al., 1998; Cerf et al., 2006). In newborn HFD offspring, we observed a greater density of peptideexpressing neurons, raising the possibility that the prenatal diet exposure may be increasing the number of cells born during gestation. This effect was site specific, localized to the anterior parvocellular PVN for GAL and middle-to-posterior PVN for ENK and DYN and to both the perifornical and lateral hypothalamic areas for ORX and $\mathrm{MCH}$.

Investigation of the mechanism underlying this neuronal change revealed an increase in the generation of new cells and neurons in the hypothalamus in response to in utero HFD. As with the changes in gene expression, this phenomenon was evident at P15 in the HFD-BD as well as HFD offspring, thus not reversible by normalizing the diet, and it occurred only in the PVN and PFLH. It was not seen in the hippocampus, where a HFD in adult rats reduces cell density (Lindqvist et al., 2006). It was also not evident in the ARC, where the orexigenic peptides are reduced by dietary fat or lipids in adult rats (Chang et al., 2004; Leibowitz and Wortley, 2004) as shown here in HFD offspring, and also where they are particularly responsive to leptin, insulin, and glucose (Leibowitz and Wortley, 2004; Simerly, 2008), which were unaltered in the HFD offspring and dams and thus unlikely to play a major role in the developmental changes.

Although many cells with a glial phenotype were evident in the hypothalamic ventricular area or forebrain regions, the PVN and PFLH had relatively few even at P25, confirming reports that mature glia in the hypothalamus develop considerably later than neurons (Jacobson, 1991). Prenatal exposure to the HFD had no effect on glial density in these areas. Further, in both the HFD-BD and HFD offspring, a significantly higher proportion of the newly generated neurons had a specific phenotype of expressing orexigenic peptides, GAL, ENK, and DYN in the PVN and ORX and $\mathrm{MCH}$ in the PFLH. These results demonstrate, for the first time, 
that dietary fat can stimulate the generation of specific new neurons, thus affecting neuronal phenotype and presumably neuronal differentiation. Although the mechanisms determining hypothalamic neuronal phenotype are not well understood, a possible role for transcription factors in this process is suggested by evidence that Shh can specify the identity of hypothalamic dopamine neurons in chick embryos (Ohyama et al., 2005) and that POU domain transcription factors like Brn-2 are required for the specification of neuronal lineages in developing hypothalamus ( $\mathrm{Na}$ kai et al., 1995). Interestingly, Shh is active only when bound to cholesterol (Ohyama et al., 2005), which is known to be elevated by prenatal HFD (Brown et al., 1990).

Further, examination of NEP at E14 revealed a stimulatory effect of in utero HFD exposure on the density of progenitor cells, NRP (Tuj1) rather than GRP (Nestin), as well as on mature new neurons (NeuN/BrdU) and migrating neurons (Dcx) at and around the third ventricle. An increase in the density of both NRP cells and neurons indicates that there was increased differentiation of NEP into these cell types, making more postmitotic neurons available to populate different hypothalamic areas. It also suggests that neuronal proliferation rather than cell survival is more likely to be responsible for the increase in new neurons seen postnatally. This is supported by the short-term nature of our experimental paradigm, which examined proliferating cells $3 \mathrm{~h}$ after BrdU injection before their final differentiation or migration. This paradigm allowed us to avoid cell death events that occur during the translocation of postmitotic cells out of the proliferative zone and into differentiating tissue (Barres et al., 1992). Although the phenomenon of cell death needs further investigation, it is noteworthy that NEP lacks neurotrophin TrkC receptors known to be important for cell survival (Hassink et al., 1999). A possible mechanism underlying the HFD-induced increase in neurogenesis may involve changes in the cell-cycle kinetics, as suggested for the dopamine system in the brain (Ohtani et al., 2003).

The proliferative and differentiating effects of the maternal HFD may involve the actions of growth factors, which are known to regulate hypothalamic neurogenesis at its different stages. These may include insulin-like growth factor-1, which is regulated maternally and fetally by nutrient availability (Gluckman et al., 1996), fibroblast growth factor whose injection into the hypothalamic third ventri-
A

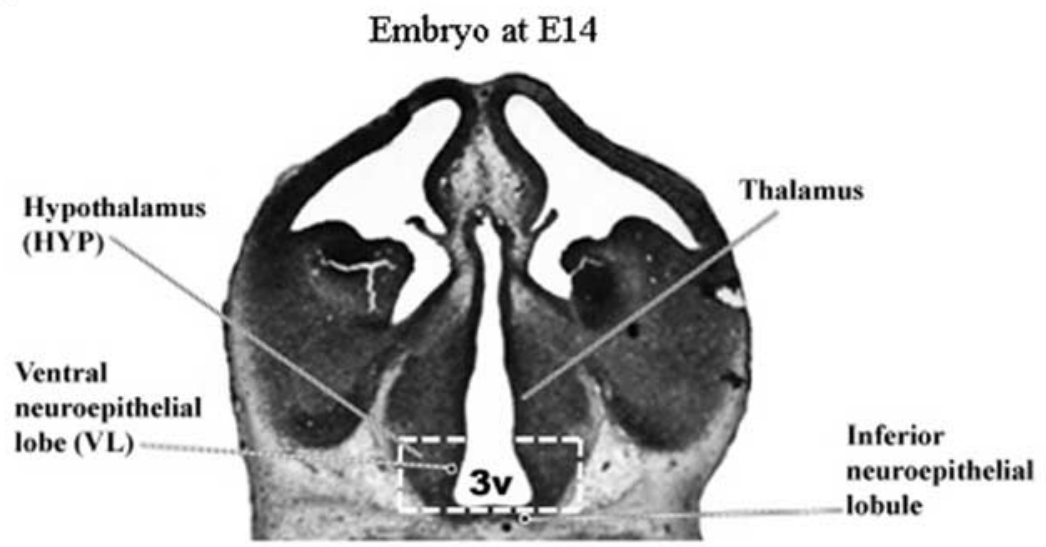

B
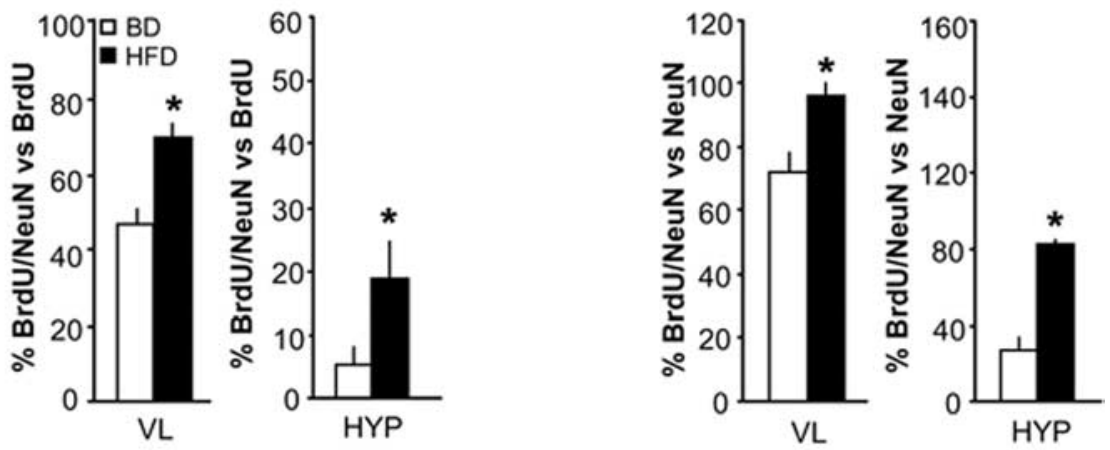

C
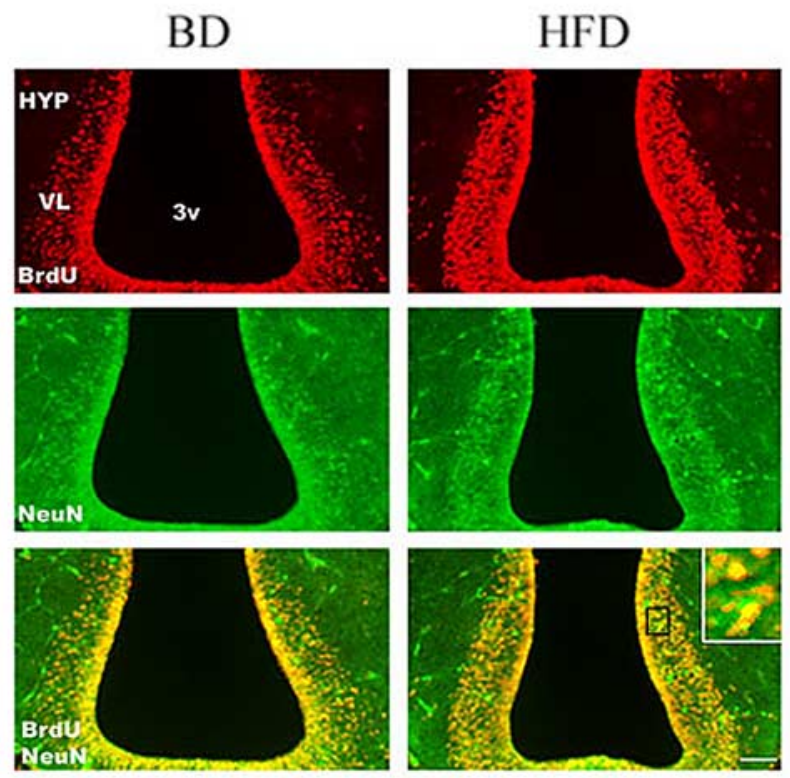

Figure 8. Embryos of HFD dams at E14 exhibited an increase in neurogenesis compared with embryos of BD dams ( $n=$ 4-6/diet group). $\boldsymbol{A}$, The dash box in the coronal section shows the ventral neuroepithelial lobe (VL) of the hypothalamic third ventricle (3v) and the surrounding hypothalamic area (HYP). B, C, The enhanced neurogenesis in HFD embryos is demonstrated by double-labeling immunofluorescence revealing an increase $\left({ }^{*} p<0.05\right)$ in the percentage of $\mathrm{BrdU}{ }^{+} / \mathrm{NeuN}^{+}$newborn neurons relative to the total number of single-labeled BrdU ${ }^{+}$cells (left) or NeuN ${ }^{+}$neurons (right) in the VL and HYP (mean \pm SEM) $(\boldsymbol{B})$; and immunofluorescence photomicrographs of HFD versus BD embryos illustrating an increase in BrdU ${ }^{+}$cells (red, top panel), $\mathrm{NeuN}^{+}$neurons (green, middle panel), and double-labeled BrdU ${ }^{+}+\mathrm{NeuN}^{+}$newborn neurons (yellow, bottom panel) in the VL, with a small effect in the HYP adjacent to the VL (scale bar: $100 \mu \mathrm{m})(\boldsymbol{C})$. The inset in bottom panel for HFD embryo, showing an enlargement of the area indicated by a box, illustrates examples of double-labeled neurons (yellow) detected in the VL. 
A

Dcx

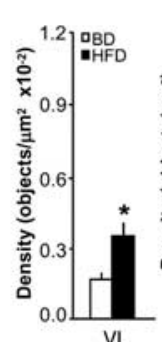

B
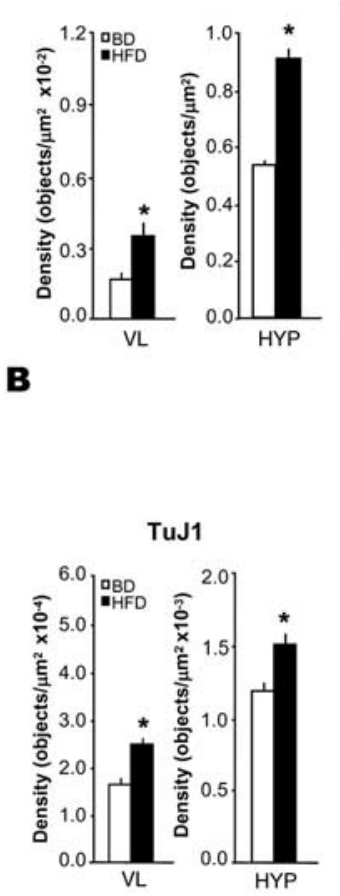

C

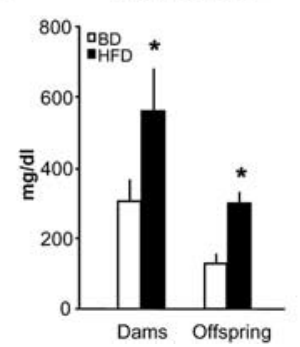

BD

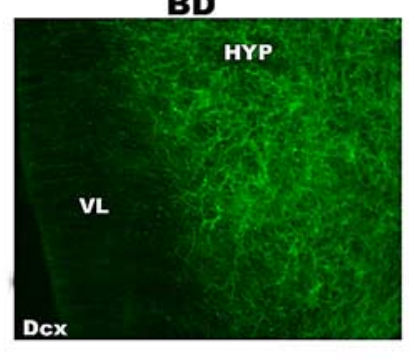

BD

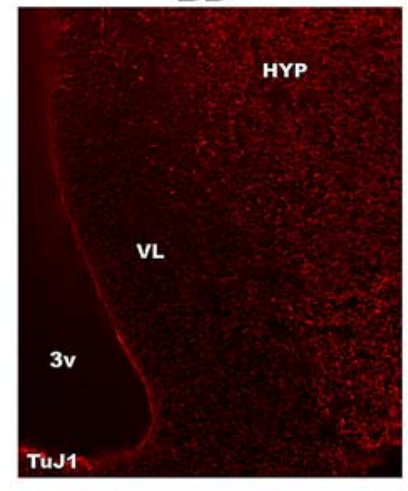

NEFA

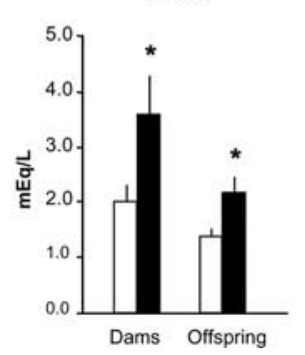

Figure 9. Embryos of HFD dams at E14 exhibited an increase in the development of neuronal precursor cell phenotype compared with embryos of BD dams ( $n=4-6 /$ diet group). This is demonstrated by single-labeling immunofluorescence, which revealed the following in the HFD versus BD embryos: an increased density $\left({ }^{*} p<0.05\right)$ in the HFD embryos of Dcx ${ }^{+}$neurons in the ventral neuroepithelial lobe (VL) of the third ventricle (3v) and surrounding hypothalamic (HYP) area (left) [this is illustrated to the right by photomicrographs of $\mathrm{Dcx}{ }^{+}$neurons (green) that are considerably more dense in the HYP while still evident in the VL of HFD embryos but not BD embryos (scale bar: $200 \mu \mathrm{m})](\boldsymbol{A})$; and an increased density $\left({ }^{*} p<0.05\right)$ of TuJ1 ${ }^{+}$neuronal precursor cells in the VL and HYP (left), as illustrated to the right by photomicrographs of TuJ1 ${ }^{+}$cells (red) in these areas surrounding the $3 \mathrm{v}$ (scale bar: $100 \mu \mathrm{m})(\boldsymbol{B})$. C, Analyses of serum from pregnant dams (E14-E18) and newborn offspring (P0) revealed significantly elevated $\left({ }^{*} p<0.01\right)$ circulating levels of triglycerides and NEFA. Data are mean \pm SEM.

cle of adult rats enhances cell proliferation in the ependymal layer (Xu et al., 2005), and brain-derived neurotrophic factor, which enhances differentiation of cultured dopaminergic neurons in the hypothalamus (Loudes et al., 1999) and is stimulated by a HFD (Archer et al., 2005). Although such hormones as insulin and leptin may have proliferative effects acting as growth factors (Baskin et al., 1987; Simerly, 2008), they were not altered in the HFD dams or their offspring before P15 and thus unlikely to play a critical role in the dietinduced neuronal changes. However, in agreement with published reports (Guo and Jen, 1995; Srinivasan et al., 2006), TG levels were markedly and consistently elevated in serum of pregnant dams on the HFD, as well as in the offspring at birth and postnatally even after the HFD was removed. The possibility that these lipids may contribute to the in utero effects of dietary fat is supported by evidence that fatty acids can stimulate neuronal proliferation and differentiation in vivo and in vitro (Kawakita et al., 2006).

In summary, the results described in this report provide novel evidence for a mechanism of fetal programming that links a maternal fat-rich diet during pregnancy to the overeating and increased weight gain of the offspring after weaning. The proposed mechanism (Fig. 10) involves (1) circulating lipids, which are elevated in the dams and offspring by in utero HFD exposure; (2) a stimulatory effect on the proliferation of NEP cells at the hypothalamic third ventricle; (3) an increase in their differentiation into neuronal precursor cells and neurons that migrate to areas destined to become the PVN and PFLH; (4) a gearing of these neurons toward a phenotype of expressing specific peptides

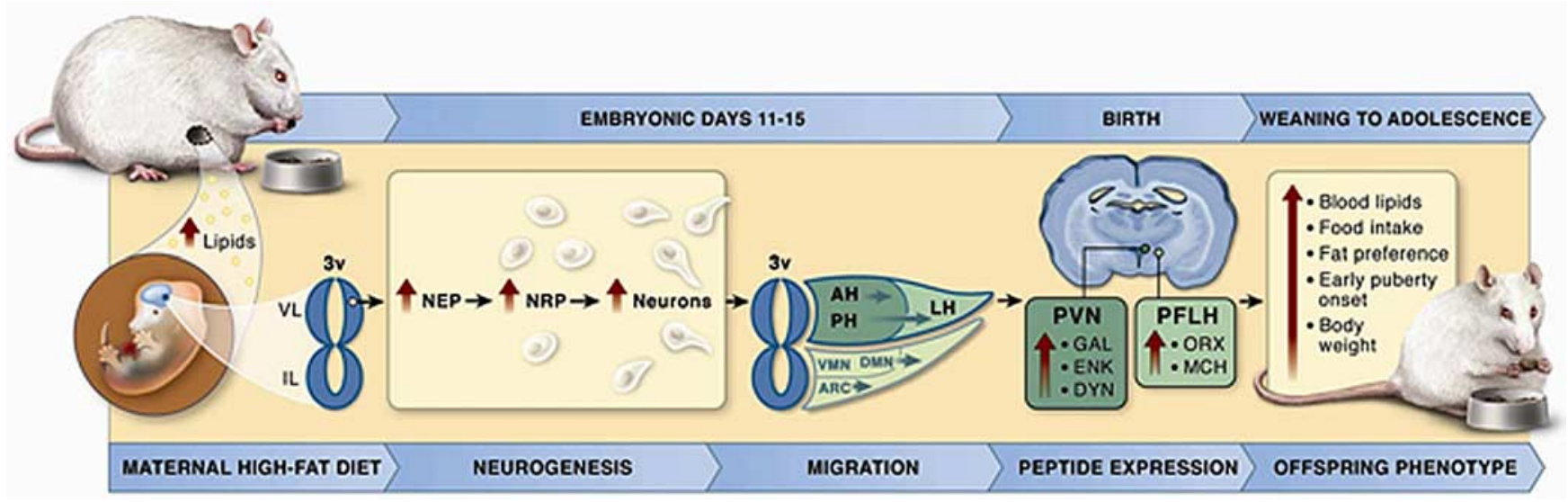

Figure 10. This diagram provides a schematic representation of the effects that prenatal HFD exposure has on circulating lipids, neuronal proliferation, differentiation, and migration, peptide gene expression in the PVN and PFLH, and the physiological and behavioral phenotype of the male offspring after weaning through adolescence. $3 \mathrm{v}$, Third ventricle; AH, anterior hypothalamus; IL, inferior neuroepithelial lobule; PH, posterior hypothalamus. 
highly responsive to a HFD; (5) enhanced expression and production of these peptides that continue until weaning and beyond, in the absence of the HFD; and (6) behavioral and physiological changes after weaning in both male and female offspring, including increased fat preference and weight gain, which are consistent with effects attributed to the orexigenic peptides. In light of a recent study of GAL deficient mice (Adams et al., 2008), we propose that the physiological purpose of this diet-induced neurogenesis is to prepare the postweaning offspring of HFD dams to consume and thrive on their diet. Although future studies need to define the precise mechanisms underlying the relationship between lipids, hypothalamic neurogenesis, and their long-term functional consequences, our findings focus on the hypothalamic NEP as an important target site of in utero HFD exposure. This provides a key step toward understanding mechanisms of fetal programming, possibly associated with the rise in fat consumption in earlier generations (Stephen and Wald, 1990), that may contribute to the increased prevalence of childhood obesity over the past 30 years.

\section{References}

Adams AC, Clapham JC, Wynick D, Speakman JR (2008) Feeding behaviour in galanin knockout mice supports a role of galanin in fat intake and preference. J Neuroendocrinol 20:199-206.

Akabayashi A, Koenig JI, Watanabe Y, Alexander JT, Leibowitz SF (1994a) Galanin-containing neurons in the paraventricular nucleus: a neurochemical marker for fat ingestion and body weight gain. Proc Natl Acad Sci U S A 91:10375-10379.

Akabayashi A, Watanabe Y, Wahlestedt C, McEwen BS, Paez X, Leibowitz SF (1994b) Hypothalamic neuropeptide $Y$, its gene expression and receptor activity: relation to circulating corticosterone in adrenalectomized rats. Brain Res 665:201-212.

Altman J, Bayer SA (1978) Development of the diencephalon in the rat. II. Correlation of the embryonic development of the hypothalamus with the time of origin of its neurons. J Comp Neurol 182:973-993.

Archer ZA, Rayner DV, Barrett P, Balik A, Duncan JS, Moar KM, Mercer JG (2005) Hypothalamic energy balance gene responses in the SpragueDawley rat to supplementation of high-energy diet with liquid ensure and subsequent transfer to chow. J Neuroendocrinol 17:711-719.

Barres BA, Hart IK, Coles HS, Burne JF, Voyvodic JT, Richardson WD, Raff MC (1992) Cell death in the oligodendrocyte lineage. J Neurobiol 23:1221-1230.

Baskin DG, Figlewicz DP, Woods SC, Porte D Jr, Dorsa DM (1987) Insulin in the brain. Annu Rev Physiol 49:335-347.

Beck B, Kozak R, Moar KM, Mercer JG (2006) Hypothalamic orexigenic peptides are overexpressed in young Long-Evans rats after early life exposure to fat-rich diets. Biochem Biophys Res Commun 342:452-458.

Brown SA, Rogers LK, Dunn JK, Gotto AM Jr, Patsch W (1990) Development of cholesterol homeostatic memory in the rat is influenced by maternal diets. Metabolism 39:468-473.

Cerf ME, Muller CJ, Du Toit DF, Louw J, Wolfe-Coote SA (2006) Hyperglycaemia and reduced glucokinase expression in weanling offspring from dams maintained on a high-fat diet. Br J Nutr 95:391-396.

Chang GQ, Karatayev O, Davydova Z, Leibowitz SF (2004) Circulating triglycerides impact on orexigenic peptides and neuronal activity in hypothalamus. Endocrinology 145:3904-3912.

Chang GQ, Karatayev O, Ahsan R, Gaysinskaya V, Marwil Z, Leibowitz SF (2007) Dietary fat stimulates endogenous enkephalin and dynorphin in the paraventricular nucleus: role of circulating triglycerides. Am J Physiol Endocrinol Metab 292:E561-570.

Clegg DJ, Air EL, Woods SC, Seeley RJ (2002) Eating elicited by orexin-a, but not melanin-concentrating hormone, is opioid mediated. Endocrinology 143:2995-3000.

Debassio WA, Kemper TL, Galler JR, Tonkiss J (1994) Prenatal malnutrition effect on pyramidal and granule cell generation in the hippocampal formation. Brain Res Bull 35:57-61.

Dourmashkin JT, Chang GQ, Hill JO, Gayles EC, Fried SK, Leibowitz SF (2006) Model for predicting and phenotyping at normal weight the longterm propensity for obesity in Sprague-Dawley rats. Physiol Behav 87:666-678.
Férézou-Viala J, Roy AF, Sérougne C, Gripois D, Parquet M, Bailleux V, Gertler A, Delplanque B, Djiane J, Riottot M, Taouis M (2007) Longterm consequences of maternal high-fat feeding on hypothalamic leptin sensitivity and diet-induced obesity in the offspring. Am J Physiol Regul Integr Comp Physiol 293:R1056-1062.

Franke K, Harder T, Aerts L, Melchior K, Fahrenkrog S, Rodekamp E, Ziska T, Van Assche FA, Dudenhausen JW, Plagemann A (2005) 'Programming' of orexigenic and anorexigenic hypothalamic neurons in offspring of treated and untreated diabetic mother rats. Brain Res 1031:276-283.

Ghosh P, Bitsanis D, Ghebremeskel K, Crawford MA, Poston L (2001) Abnormal aortic fatty acid composition and small artery function in offspring of rats fed a high fat diet in pregnancy. J Physiol 533:815-822.

Gluckman PD, Cutfield W, Harding JE, Milner D, Jensen E, Woodhall S, Gallaher B, Bauer M, Breier BH (1996) Metabolic consequences of intrauterine growth retardation. Acta Paediatr Suppl 417:3-6; discussion 7.

Gressens P, Muaku SM, Besse L, Nsegbe E, Gallego J, Delpech B, Gaultier C, Evrard P, Ketelslegers JM, Maiter D (1997) Maternal protein restriction early in rat pregnancy alters brain development in the progeny. Brain Res Dev Brain Res 103:21-35.

Guo F, Jen KL (1995) High-fat feeding during pregnancy and lactation affects offspring metabolism in rats. Physiol Behav 57:681-686.

Hassink GC, van Esseveldt KE, Dijkhuizen PA, Verhaagen J, Boer GJ (1999) Ontogeny of neurotrophin receptor trkC expression in the rat forebrain and anterior hypothalamus with emphasis on the suprachiasmatic nucleus. Neuroscience 92:705-712.

Ifft JD (1972) An autoradiographic study of the time of final division of neurons in rat hypothalamic nuclei. J Comp Neurol 144:193-204.

Jacobson M (1991) Developmental neurobiology, Ed 3. New York: Plenum.

Kawakita E, Hashimoto M, Shido O (2006) Docosahexaenoic acid promotes neurogenesis in vitro and in vivo. Neuroscience 139:991-997.

Kennedy AR, Pissios P, Otu H, Xue B, Asakura K, Furukawa N, Marino FE, Liu FF, Kahn BB, Libermann TA, Maratos-Flier E, Roberson R (2007) A high-fat, ketogenic diet induces a unique metabolic state in mice. Am J Physiol Endocrinol Metab 292:E1724-1739.

Khan IY, Dekou V, Douglas G, Jensen R, Hanson MA, Poston L, Taylor PD (2005) A high-fat diet during rat pregnancy or suckling induces cardiovascular dysfunction in adult offspring. Am J Physiol Regul Integr Comp Physiol 288:R127-R133.

Kozak R, Mercer JG, Burlet A, Moar KM, Burlet C, Beck B (1998) Hypothalamic neuropeptide $\mathrm{Y}$ content and mRNA expression in weanling rats subjected to dietary manipulations during fetal and neonatal life. Regul Pept 75-76:397-402.

Leibowitz SF (2000) Macronutrients and brain peptides: what they do and how they respond. In: Neural and metabolic control of macronutrient intake (Berthoud H-R, Seeley RJ, eds), pp 389-406. Boca Raton, FL: CRC.

Leibowitz SF, Wortley KE (2004) Hypothalamic control of energy balance: different peptides, different functions. Peptides 25:473-504.

Leibowitz SF, Akabayashi A, Wang J (1998) Obesity on a high-fat diet: role of hypothalamic galanin in neurons of the anterior paraventricular nucleus projecting to the median eminence. J Neurosci 18:2709-2719.

Leibowitz SF, Dourmashkin JT, Chang GQ, Hill JO, Gayles EC, Fried SK, Wang J (2004) Acute high-fat diet paradigms link galanin to triglycerides and their transport and metabolism in muscle. Brain Res 1008:168-178.

Leibowitz SF, Akabayashi A, Wang J, Alexander JT, Dourmashkin JT, Chang GQ (2007) Increased caloric intake on a fat-rich diet: role of ovarian steroids and galanin in the medial preoptic and paraventricular nuclei and anterior pituitary of female rats. J Neuroendocrinol 19:753-766.

Lindqvist A, Mohapel P, Bouter B, Frielingsdorf H, Pizzo D, Brundin P, Erlanson-Albertsson C (2006) High-fat diet impairs hippocampal neurogenesis in male rats. Eur J Neurol 13:1385-1388.

Liu Y, Wu Y, Lee JC, Xue H, Pevny LH, Kaprielian Z, Rao MS (2002) Oligodendrocyte and astrocyte development in rodents: an in situ and immunohistological analysis during embryonic development. Glia 40:25-43.

López M, Seoane LM, Tovar S, García MC, Nogueiras R, Diéguez C, Señarís RM (2005) A possible role of neuropeptide Y, agouti-related protein and leptin receptor isoforms in hypothalamic programming by perinatal feeding in the rat. Diabetologia 48:140-148.

Loudes C, Petit F, Kordon C, Faivre-Bauman A (1999) Distinct populations of hypothalamic dopaminergic neurons exhibit differential responses to 
brain-derived neurotrophic factor (BDNF) and neurotrophin-3 (NT3). Eur J Neurosci 11:617-624.

Lucas F, Ackroff K, Sclafani A (1998) High-fat diet preference and overeating mediated by postingestive factors in rats. Am J Physiol 275:R1511-R1522.

Markakis EA (2002) Development of the neuroendocrine hypothalamus. Front Neuroendocrinol 23:257-291.

Markakis EA, Swanson LW (1997) Spatiotemporal patterns of secretomotor neuron generation in the parvicellular neuroendocrine system. Brain Res Brain Res Rev 24:255-291.

McMillen IC, Robinson JS (2005) Developmental origins of the metabolic syndrome: prediction, plasticity, and programming. Physiol Rev 85:571-633.

Nakai S, Kawano H, Yudate T, Nishi M, Kuno J, Nagata A, Jishage K, Hamada H, Fujii H, Kawamura K, et al (1995) The POU domain transcription factor Brn-2 is required for the determination of specific neuronal lineages in the hypothalamus of the mouse. Genes Dev 9:3109-3121.

Ohtani N, Goto T, Waeber C, Bhide PG (2003) Dopamine modulates cell cycle in the lateral ganglionic eminence. J Neurosci 23:2840-2850.

Ohyama K, Ellis P, Kimura S, Placzek M (2005) Directed differentiation of neural cells to hypothalamic dopaminergic neurons. Development 132:5185-5197.

Plagemann A (2006) Perinatal nutrition and hormone-dependent programming of food intake. Horm Res 65 [Suppl 3]:83-89.

Plagemann A, Harder T, Lindner R, Melchior K, Rake A, Rittel F, Rohde W, Dörner G (1998) Alterations of hypothalamic catecholamines in the newborn offspring of gestational diabetic mother rats. Brain Res Dev Brain Res 109:201-209.

Plagemann A, Harder T, Rake A, Voits M, Fink H, Rohde W, Dörner G (1999) Perinatal elevation of hypothalamic insulin, acquired malformation of hypothalamic galaninergic neurons, and syndrome X-like alterations in adulthood of neonatally overfed rats. Brain Res 836:146-155.

Plagemann A, Harder T, Rake A, Melchior K, Rohde W, Dörner G (2000) Hypothalamic nuclei are malformed in weanling offspring of low protein malnourished rat dams. J Nutr 130:2582-2589.

Qian X, Shen Q, Goderie SK, He W, Capela A, Davis AA, Temple S (2000) Timing of CNS cell generation: a programmed sequence of neuron and glial cell production from isolated murine cortical stem cells. Neuron 28:69-80.

Rao M (2004) Stem and precursor cells in the nervous system. J Neurotrauma 21:415-427.

Reagan LP, Rosell DR, Wood GE, Spedding M, Muñoz C, Rothstein J, McEwen BS (2004) Chronic restraint stress up-regulates GLT-1 mRNA and protein expression in the rat hippocampus: reversal by tianeptine. Proc Natl Acad Sci U S A 101:2179-2184.

Rocchini AP (2002) Childhood obesity and a diabetes epidemic. N Engl J Med 346:854-855.

Sherwood NM, Timiras PS (1970) A stereotaxic atlas of the developing rat brain. Los Angeles: University of California.
Simerly RB (2008) Hypothalamic substrates of metabolic imprinting. Physiol Behav 94:79-89.

Singh BS, Westfall TC, Devaskar SU (1997) Maternal diabetes-induced hyperglycemia and acute intracerebral hyperinsulinism suppress fetal brain neuropeptide Y concentrations. Endocrinology 138:963-969.

Srinivasan M, Aalinkeel R, Song F, Mitrani P, Pandya JD, Strutt B, Hill DJ, Patel MS (2006) Maternal hyperinsulinemia predisposes rat fetuses for hyperinsulinemia, and adult-onset obesity and maternal mild food restriction reverses this phenotype. Am J Physiol Endocrinol Metab 290:E129-E134.

Stephen AM, Wald NJ (1990) Trends in individual consumption of dietary fat in the United States, 1920-1984. Am J Clin Nutr 52:457-469.

Taylor PD, Poston L (2007) Developmental programming of obesity in mammals. Exp Physiol 92:287-298.

Taylor PD, McConnell J, Khan IY, Holemans K, Lawrence KM, Asare-Anane H, Persaud SJ, Jones PM, Petrie L, Hanson MA, Poston L (2005) Impaired glucose homeostasis and mitochondrial abnormalities in offspring of rats fed a fat-rich diet in pregnancy. Am J Physiol Regul Integr Comp Physiol 288:R134-139.

Terroni PL, Anthony FW, Hanson MA, Cagampang FR (2005) Expression of agouti-related peptide, neuropeptide $\mathrm{Y}$, pro-opiomelanocortin and the leptin receptor isoforms in fetal mouse brain from pregnant dams on a protein-restricted diet. Brain Res Mol Brain Res 140:111-115.

Tritos NA, Elmquist JK, Mastaitis JW, Flier JS, Maratos-Flier E (1998) Characterization of expression of hypothalamic appetite-regulating peptides in obese hyperleptinemic brown adipose tissue-deficient (uncoupling protein-promoter-driven diphtheria toxin A) mice. Endocrinology 139:4634-4641.

Welch CC, Kim EM, Grace MK, Billington CJ, Levine AS (1996) Palatability-induced hyperphagia increases hypothalamic Dynorphin peptide and mRNA levels. Brain Res 721:126-131.

Wortley KE, Chang GQ, Davydova Z, Leibowitz SF (2003) Peptides that regulate food intake: orexin gene expression is increased during states of hypertriglyceridemia. Am J Physiol Regul Integr Comp Physiol 284:R1454-R1465.

Xu Y, Tamamaki N, Noda T, Kimura K, Itokazu Y, Matsumoto N, Dezawa M, Ide C (2005) Neurogenesis in the ependymal layer of the adult rat 3rd ventricle. Exp Neurol 192:251-264.

Yanagisawa M, Takizawa T, Ochiai W, Uemura A, Nakashima K, Taga T (2001) Fate alteration of neuroepithelial cells from neurogenesis to astrocytogenesis by bone morphogenetic proteins. Neurosci Res 41:391-396.

Yun R, Dourmashkin JT, Hill J, Gayles EC, Fried SK, Leibowitz SF (2005) PVN galanin increases fat storage and promotes obesity by causing muscle to utilize carbohydrate more than fat. Peptides 26:2265-2273.

Zhang M, Gosnell BA, Kelley AE (1998) Intake of high-fat food is selectively enhanced by mu opioid receptor stimulation within the nucleus accumbens. J Pharmacol Exp Ther 285:908-914. 